\title{
Economic potential of adopting genomic technology in Alberta's tree improvement sector
}

\author{
by Shuo Wang ${ }^{1}$, Henry An²\%, Wei-Yew Chang ${ }^{3}$, Chris Gaston ${ }^{4}$, Barb R. Thomas ${ }^{5}$
}

\begin{abstract}
The adoption of genomic technology and the use of improved seeds are expected to improve timber productivity in Alberta. However, this improvement will need to take place within the confines of the public-private nature of the sector where $93 \%$ of the total forest area is publicly owned. The purpose of this study is to explore the extent to which a timber harvest policy known as the allowable cut effect can affect the welfare outcomes of adopting genomics-assisted tree breeding. Using the forest industry of Alberta as the empirical setting, the economic returns to the adoption of this new breeding technology in lodgepole pine (Pinus contorta Dougl. ex Loud. var. latifolia Engelm.) and white spruce (Picea glauca (Moench) Voss) are calculated by estimating a timber supply model and a spatial equilibrium model. Under certain policy and technology improvement scenarios, the economic returns are negative, which would result in non-adoption of the technology. However, under other feasible conditions, the payoffs of genomics-assisted tree breeding research are large and positive. These results illustrate the important role that government policies can have on the returns to adopting new technologies.
\end{abstract}

Keywords: allowable cut effect; forestry; genomics; mathematical programming; returns to R\&D; tree improvement JEL classification: Q16; Q17; Q18; Q23; C61; C63

\section{RÉSUMÉ}

L’adoption des technologies génomiques et l'utilisation de semences améliorées devraient accroître la productivité forestière du bois de sciage en Alberta. Cependant, cet accroissement est appelé à survenir dans les limites du contexte publicprivé de propriété des forêts selon lequel $93 \%$ de la superficie forestière totale est de nature publique. L'objectif de cette étude est d'étudier jusqu'à quel point les politiques de récoltes du bois, notamment la coupe annuelle permise, peuvent avoir un impact sur les retombées socio-économiques suite à l'adoption d'un programme d'amélioration génétique des arbres. En utilisant l'industrie forestière de l'Alberta en tant que contexte empirique, les retombées économiques de l'adoption de cette nouvelle technologie d'amélioration génétique dans le cas du pin lodgepole (Pinus contorta Dougl. ex Loud. var. latifolia Engelm.) et de l'épinette blanche (Picea glaucsa (Moench) Voss) ont été calculées en fonction d'estimations tirées d'un modèle d'approvisionnement en matière ligneuse et d'un modèle de distribution spatiale. Dans le cas de certains scénarios de politiques et de technologies d'amélioration, les retombées économiques sont négatives, ce qui entraînerait un rejet de la technologie. Cependant selon certaines conditions de faisabilité, les retombées de la recherche axée sur l'amélioration reposant sur des techniques génétiques, sont importantes et positives. Ces résultats illustrent l'importance des politiques gouvernementales sur les retombées économiques lors de l'adoption de nouvelles technologies.

Mots clés : effet de la coupe annuelle permise; foresterie; génomique; programmation mathématique; retombées des recherches et du développement classification JEL : Q16; Q17; Q18; Q23; C61; C63

\section{Introduction}

Genomics is broadly defined as the mapping, sequencing and analysis of genomes (Xu 2006). In the case of animal and plant breeding, the use of genomics involves examining the entire genome of an organism to identify genetic markers that are correlated with economically valuable traits. It is important to note that genomics does not refer to an explicit and directed transformation or modification of the underlying DNA. Instead, the information that is gathered from sequencing the DNA of the organism is used to produce more robust models linking the phenotype (actual realized physical traits) to its specific genotype (underlying DNA). The basis of tree improvement is in the process of growing, testing, and selecting individuals with desirable traits that are heritable, which allows the improvement to be passed on from parent to progeny. The advantage of genomics over traditional breeding programs is that it makes use of both genetic and phenotypic information which can greatly increase the ability - in terms of both speed and accuracy - to select for the best animals or plants. Public funding agencies in Canada have invested approximately $\$ 480$ million (all values in CAD) in genomics-based technologies in the agri-food

\footnotetext{
${ }_{1}^{1}$ Department of Agricultural and Resource Economics, University of Maryland, Symons Hall, College Park, Maryland, USA 20742

${ }^{2}$ Department of Resource Economics \& Environmental Sociology, University of Alberta, 551 General Services Building, Edmonton, Alberta, Canada T6G 2H1 *Corresponding author: henry.an@ualberta.ca

${ }^{3}$ School of Economics, Lanzhou University, No. 222 South Tianshui Road, Lanzhou, Gansu, China 730000

${ }^{4}$ Department of Wood Science, University of British Columbia, 4028 Forest Sciences Centre, Vancouver, British Columbia, Canada V6T $1 Z 4$

${ }^{5}$ Department of Renewable Resources, University of Alberta, 442 Earth Sciences Building, Edmonton, Alberta, Canada T6G 2E3
} 
and forest sectors in the past 15 years (Genome Canada 2017). With all these investments being made, a key question to ask is: what are the economic impacts of this research and development (R\&D) effort? This question is especially important now when government investments in science are under scrutiny to demonstrate impact (Hope et al. 2017).

Tree improvement is one of the key silviculture activities that forest companies can use to increase the productivity of forestland and ultimately harvests. Traditional tree breeding of boreal conifer species takes about 30 years to complete one breeding cycle-with a rotation age of approximately 80 years-making it difficult to respond quickly to external changes (e.g., climate change, new regulations, and changes in the market). With the adoption of genomic technologyspecifically, genomics-assisted tree breeding - the tree breeding cycle can be significantly shortened: by up to 20 years in some cases (Chang et al. 2019). This can have significant effects on investment decisions due to the discounted nature of future benefits. Moreover, genomic selection delivers more accurate breeding values and allows for a higher intensity of selection $^{6}$ than traditional breeding methods (Porth et al. 2015; Ratcliffe et al. 2017). Though the benefits of genomic technology have been widely recognized by the scientific community (e.g., Resende et al. 2012), to date, no forest products company in Canada has adopted genomics-assisted tree breeding into their mainstream business activity (Porth et al. 2016). This may be due to a lack of government support in any current forest management framework found across the country or to a lack of evidence on the industrial benefits of adopting the technology. In particular, how has the "allowable cut effect" (ACE) affected the incentive to invest in new productivity-enhancing technologies?

ACE is defined as an immediate increase in today's allowable cut which is attributable to expected future increases in timber yield (Schweitzer et al. 1972). The annual allowable cut is the amount of timber that can be harvested each year and is determined by forest managers to ensure sustainability. The ACE is a policy measure that permits forest companies to harvest more timber in the current time period in exchange for the company investing in tree improvement and regeneration, which is expected to increase forest volume in the future. The purpose of the ACE is to encourage private firms to invest in silviculture on public Crown forest lands by allowing the firms to increase production if they can show the potential for increases in their productive capacity or yield. There are many factors that the government considers before granting an ACE, most of which are related to demonstrating that increases in current harvests do not have long-term negative effects on future harvests. This may include a consideration of the effects of increased harvesting on the age class structure (i.e., the proportion of trees in different age classes) of the forest management unit. Provincial governments are responsible for implementing this policy, and generally manage public forestlands through a series of licensing arrangements, or Crown forest tenures (Luckert and Haley 1995).

While the idea of an ACE has been around in Canada

\footnotetext{
"Selection intensity is a measure of how much "better" the selected parent genotypes are compared with an average population and is expressed in units of standard deviations from the mean. It is directly related to the potential genetic gain that you can achieve in the offspring.
}

since the 1990s, under the enhanced forest management policy framework, the ACE has been largely unsuccessful as a policy instrument in that it has not been able to increase voluntary private investments (Luckert and Haley 1995). The main factors contributing to the failure of the ACE are identified as rent collection provisions (e.g., stumpage fees) that prevent firms from achieving enough financial returns on investment, nonbinding harvesting constraints, and the high cost of having an ACE approved and uncertainties surrounding crown tenure rights (Luckert and Haley 1995). However, a more recent analysis of this policy is lacking, and it is possible that the ACE can be an effective policy tool in today's environment. Re-examining the effectiveness of the ACE as a tree improvement strategy is important because the emergence of genomics-based tree improvement techniques may have changed the economic payoffs that previously were not large enough to induce firms to invest in tree improvement.

The main question addressed in this paper is: to what extent can the ACE policy be used to motivate forest companies under current market and technological conditions to invest in tree improvement and genomic technology? This is accomplished by estimating how changes to the ACE affect the economic surplus and returns to $R \& D$ for genomicsassisted tree breeding. Specifically, it is assumed that the genetic gain (i.e., increase in wood volume at rotation) achieved by using genomic technology can be fully transferred into the ACE and estimate the economic returns on forestry genomics R\&D investments. Then, the possibility that genetic gain achieved by using genomic technology will not be fully transferred into the $\mathrm{ACE}^{7}$ is considered and estimated, with a range of potential economic returns examined by conducting sensitivity analyses.

This study is part of a larger project titled "Resilient Forests (RES-FOR): Climate, Pests \& Policy-Genomic Applications" that is funded by Genome Canada and Genome Alberta, among others. The purpose of the RESFOR project is to integrate phenotyping and genotyping capabilities to enable early identification and incorporation of more desirable and adaptive traits into future forest breeding stock. The RES-FOR project only focuses on lodgepole pine (Pinus contorta Dougl. ex Loud. var. latifolia Engelm.) and white spruce (Picea glauca (Moench) Voss). These two species together account for about $90 \%$ of Alberta's merchantable volume of coniferous growing stock and are predominately used for the production of softwood lumber (SWL) (Alberta Agriculture and Forestry 2017). Therefore, it is appropriate to consider only the SWL industry for the economic evaluation of the RES-FOR research program.

The results of this study will be useful in guiding public and private investment decisions on genomic research and policy decisions on the use of the ACE in Alberta. While genomic technology offers numerous improvements over traditional methods, the overall welfare effect in response to the adoption of genomic technology and the use of the ACE in the tree improvement context is uncertain. The main ben-

\footnotetext{
${ }^{7}$ The decision regarding the extent to which the ACE can be approved is made by the government. Numerous factors enter the timber supply analysis as the government has multiple objectives and faces multiple constraints. These other factors can affect the final outcome and lead to the case where no increase in the AAC is granted even with the yield gain being included into the calculation.
} 
eficiaries from this technology are the forestry companies, and they stand to benefit the most if the ACE is applied more generously. However, the Government of Alberta also has an interest in seeing this important sector maintain and increase its competitiveness. For this reason, public resource owners in Canada should support R\&D that increases forest productivity (e.g., faster-growing trees) and partner with private firms. As is the case with projects that receive public funding, the problem facing policy-makers is to compare the benefits and costs for a wide variety of competing projects. This dilemma makes an assessment of the returns to genomics $\mathrm{R} \& \mathrm{D}$-which can reveal the conditions under which the adoption of genomic technology within an ACE framework is beneficial-an important and interesting area of study.

Forest genomics research is being undertaken all over the world, especially in Canada, the United States, and Sweden where forestry is a key sector (Holliday et al. 2017; Chang et al. 2019). However, to the best of our knowledge, there are no studies that have estimated the economic impact of using genomic technology to increase timber volume. The contributions of this paper go beyond its role as a case study of adopting genomic technology in Alberta. Lessons learned from this study could provide guidance to other regions interested in adopting genomic technology on how best to formulate policy to encourage the adoption of productivityenhancing technologies.

The remainder of the paper provides a review of the forest economics literature concerning the ACE policy, the economic evaluation techniques of a research program and economic impact analysis of timber and wood products market shocks, followed by an introduction to the model and model parameterization, the simulation scenarios, and a report of the estimation results. The paper concludes with a discussion of the policy implications of this paper and areas of future research.

\section{Background \\ Allowable cut effect}

In Canada, where the private sector is directly responsible for the management of public forest land, the ACE has been the major policy instrument used by Canadian provinces to encourage private investments in silviculture on Crown forests (Luckert and Haley 1995). In Alberta, although most production is organized and carried out by private entrepreneurs responding to market incentives, they are strongly influenced and constrained by the decisions and regulations of the provincial government. Alberta's commercial forests are primarily situated on Crown land and the right to harvest Crown timber is allocated to companies and individuals through an area- or volume-based tenure system (Alberta Agriculture and Forestry 2018). The Alberta government aims to provide a steady timber supply for the operating forest company to ensure that forest values are maintained for future generations (Alberta Agriculture and Forestry 2018). Forest companies operate and are responsible for the management of the forest within their respective Forest Management Agreement areas. Forest Management Plans, which are submitted and renegotiated every 10 years, are a requirement of a Forest Management Agreement (Alberta Agriculture and Forestry 2018). Each Forest Management Plan covers a forest planning horizon of 200 years and includes detailed information of where, when and how trees on Crown land will be harvested and managed (Alberta Agriculture and Forestry 2018). In Forest Management Plans, linear programming has been used extensively to characterize the dynamics of forest production and develop strategic forest management plans, especially for large industrial forest operators (e.g., West Fraser and Weyerhaeuser).

The harvest levels of each forest company are approved by the Government of Alberta through an annual allowable cut (AAC) (Schreiber and Thomas 2017). The fundamental components of an AAC determination includes quantity of available land, age class distribution of the forest, yield information, and constraints associated with managing the forest. In order to increase the allowable harvest level, forest companies have the option to engage in a range of silvicultural activities, such as using improved seeds for reforestation to increase yield. The change in AAC due to silvicultural activities is called the ACE. The ACE allows for an immediate increase in the annual harvest by the same amount each year, for the number of years in the forest rotation with an expectation of improvement in growth, even if the direct effect will not be immediately realized (Pearse 1990). The magnitude of the ACE depends on the quantity of old growth forest that is available for immediate harvesting, and the ACE can lead to accelerated harvest levels of old growth forest stock (Hegan and Luckert 2000). We address the uncertainty of the benefits arising from changes in the application of ACE by performing sensitivity analyses regarding the improved yield and adoption rate of improved seeds in a later section.

Given the potential importance of ACE, it is a little surprising that relatively few studies have explored empirically the economic incentives created by ACE for forest companies. One exception is Hegan and Luckert (2000) who used a forest level study to show that only in limited cases are there positive returns to silviculture investments and therefore little incentive exists for forest companies to undertake investments. Their study only focuses on certain specific silvicultural activities (i.e., extensive and intensive forest management) and thus the results of their study are not generally applicable to all silviculture investments or genomic technologies in particular. It is possible that the effectiveness of the ACE might be different in the tree improvement context.

\section{Tree improvement programs}

Traditional tree improvement programs consist of repeated cycles, each with distinctive breeding, testing and selection phases (Namkoong et al. 1988). At the completion of each cycle, breeders identify superior individuals which are then used in subsequent breeding cycles and elite genotypes are used to develop seed orchards for abundant production of genetically improved seed for reforestation (White et al. 2007). According to El-Kassaby et al. (2012), the traditional breeding process is resource-demanding and long-term in nature and the pedigreed offspring and subsequent testing phases are a major resource drain with time bottlenecks. The current genomics-assisted tree breeding research is being undertaken to generate advanced genomic selection techniques that can significantly reduce breeding cycle times and increase selection accuracy allowing for more rapid genetic gain. For the purposes of this paper, genetic gain at a given rotation age is defined as the predicted increase in percent volume for selected trees over wild trees; thus, the technology is "yield-enhancing". 
The literature on the economics of tree improvement programs is fairly large with much of the literature looking at the benefits of using traditional breeding programs. In the agricultural economics literature, McKenney et al. $(1989,1992)$ estimate the economic benefits of tree improvement in a Canadian context. Both of these papers use net present value to assess the economic feasibility of the research program and a simulation approach to model the benefits and costs. Byram et al. (2005) considered tree improvement programs in the United States and discussed how changes in breeding, genetics and societal issues will impact these programs. More recently, Chang et al. (2019) provide a review of the literature on the economics of tree improvement. They found that costbenefit analysis is easily the preferred empirical approach to assess the economic value of tree improvement programs for planted forests. Their review shows that most studies find positive economic benefits from these programs. This study contributes to the tree improvement literature by examining how a genomics-assisted tree breeding program compares with a traditional breeding program.

\section{Effects of market shocks in the forest sector}

The spatial equilibrium model is commonly used to analyze the spatial patterns of supply, demand, trade and pricing across regions. The advantage of the model is that it is able to predict new trade patterns easily over a long-term period by maximizing the total trade surplus (Adams and Haynes 1987). The spatial equilibrium model also allows us to perform policy analysis under different scenarios by simply altering the parameters in the objective function or constraints.

Delcourt (1995) used a spatial equilibrium trade model to examine the effects of forest policies on international trade flows of softwood lumber (SWL) and forecasts changes in SWL production, consumption and prices for seven demand regions and eight supply regions over a 38-year period from 1987 to 2025. Abbott et al. (2009) extended Delcourt's approach by incorporating uncertainty of parameters and a game-theoretic approach into the spatial equilibrium model to analyze the economic effects of mountain pine beetle outbreaks on the British Columbia forest industry.

More recently, Chang and Gaston (2014) used a recursive dynamic spatial equilibrium model to analyze the competitiveness of the Canadian SWL industry. The main contribution of their paper is that they relax the restrictive assumption of product homogeneity and disaggregate SWL into higher and lower grade lumber groups. Using similar spatial equilibrium modeling techniques, Chang and Gaston (2015) examined the global impacts of potential changes in trade policies and supply constraints in Russia and New Zealand.

This study extends previous economic analyses by explicitly considering the impact of accelerated forest growth resulting from the use of genomic selection tools on harvesting decisions (i.e., annual allowable cut), and forest product markets through a timber supply model and an economic model. Empirically, the spatial equilibrium model developed by Gaston and Marinescu (2006) and Chang and Gaston (2014) is used. The purpose of this study is to analyze the welfare effects of adopting genomic technology in the forest sector. We use a more recent dataset and examine how the uncertainties around the implementation of forestry regulations (i.e., ACE) in Alberta can affect the potential economic payoffs of adopting genomic technology. In short, this study differs in purpose, scope, and method from other studies previously conducted on the forest sector.

\section{Empirical approach}

A standard method to evaluate the impact of a new research project is to calculate the net benefits of the project and compare these with what would have taken place in its absence. In general, the goal is to construct appropriate counterfactual scenarios and then to estimate the benefits and costs of the proposed research program. A commonly used approach to evaluate the ex ante benefits of a new technology is the economic surplus model.

Economic surplus models examine how research affects supply, demand, and their resulting market outcomes. The benefits from research are measured by changes in consumers' and producers' surpluses, where any estimated gains in surplus are then compared against the estimated costs of the research. The economic surplus model offers a relatively straight-forward way of calculating the economic surplus gain brought by a new technology or the net return on R\&D, and can also provide a sense of the distribution of benefits among different stakeholders. Moreover, the economic surplus method can be used for ex ante as well as expost research evaluation. The main limitation of the model is that it is sensitive to the choice of elasticities that are used in the estimation. Since the surplus results are calculated directly using the exogenous parameters (e.g., elasticities), the accuracy of the results depends highly on the accuracy of the magnitude of the parameters. While the economic surplus model may rely on econometric estimation, in this study the demand and supply curves are calibrated instead of being econometrically estimated.

Using the economic surplus approach as the basic framework, first a timber supply simulation model is developed to quantify the increase in timber supply attributable to the use of genomic technology over a certain time period. Then the results from the timber supply model are incorporated into an economic trade model to estimate the economic effect of the projected timber supply shock. The empirical setting is the forest industry of Alberta, Canada.

\section{Timber supply model}

A timber supply model ${ }^{8}$ generates estimates of harvest volumes that are later used as an input into the spatial equilibrium model. Similar to the timber supply analysis process in firm-level Forest Management Plans, a linear programmingbased timber supply model is constructed to characterize the dynamics of the forest age structures and to examine the impact of changing forest growth functions on the provincial level AACs under different scenarios. The dynamics of the forest state are modeled using the Woodstock Forest Modeling System and the Mosek solver (Remsoft Inc. 1994). A planning horizon of 40 periods is used, with each period representing five years. Currently in Alberta, timber harvesting decisions are made without considering economic factors (i.e., maximizing total volume instead of maximizing net pre-

\footnotetext{
${ }^{8}$ Note that a "timber supply model" is not a standard economics supply model. It is simply a model that predicts the volume of wood that will be produced based on growth and yield curves (Hegan and Luckert 2000; Anderson et al. 2012).
} 
sent value as in a Faustmann-type approach). Therefore, to represent the current practice in Alberta, the harvest volume for pine and spruce is maximized subject to provincial regulatory policies and resource constraints. An illustrative model on the timber supply simulation process is presented through Eqs. (1)-(4). Let $\phi$ represent the set of all species composition strata where $\phi=\{\mathrm{C}-\mathrm{P}, \mathrm{C}-\mathrm{Sb}, \mathrm{C}-\mathrm{Sw}, \mathrm{CD}-\mathrm{P}, \mathrm{CD}-\mathrm{Sb}, \mathrm{CD}-\mathrm{Sw}$, $\mathrm{D}, \mathrm{DC}-\mathrm{P}, \mathrm{DC}-\mathrm{S}\}^{9}$. We solve the following constrained optimization problem:

$$
\operatorname{Max} T V=\sum_{s \in \phi} V_{t}^{s}
$$

Subject to:

$$
\begin{aligned}
& \text { (2) } \sum_{s \in \phi} V_{t+1}^{s}-\sum_{s \in \phi} V_{t}^{s}=0, \quad t=1, \ldots, 200 \\
& \text { (3) } \sum_{s \in \phi} Y_{t+1}^{s} A_{t+1}^{s}-\sum_{s \in \phi} Y_{t}^{s} A_{t}^{s}=0, \quad t=151, \ldots, 200 \\
& \text { (4) } V_{t}^{s}=\left\{\begin{array}{cc}
0, & \text { if } Y_{t}^{s}<50 \\
V_{t}^{s}, & \text { if } Y_{t}^{s} \geq 50
\end{array}, \quad t=1, \ldots, 200\right.
\end{aligned}
$$

where $T V$ is the total harvest volume, $V_{t}^{s}$ is the harvest volume of species strata $s$ in year $t$; $Y_{t}^{s}$ is the yield (in $\mathrm{m}^{3} / \mathrm{ha}$ ) of species strata $s$ in year $t$; $A_{t}^{s}$ is the area of species strata $s$ in year $t$. Constraint (2) ensures that an even-flow of timber harvest volume is scheduled; constraint (3) is consistent with the current forest management planning standard that the amount of operable growing stock must be stable over the last quarter of the planning horizon so that the growing stock is not completely liquidated at the end of the planning horizon (Government of Alberta 2006); and constraint (4) sets the operability limits on the clear-cut action so that no species composition strata with a standing volume of less than $50 \mathrm{~m}^{3} /$ ha is harvested (Government of Alberta 2016).

Assuming the actual harvest level is the same as the calculated $\mathrm{AAC}^{10}$, forest inventory and growth and yield data from the Government of Alberta are used as the starting values, and then the timber supply model is calibrated to the AAC level in 2015. We then simulate the annual timber supply under different scenarios. These scenarios consider different levels of genomic tree improvement or genetic gain. By incorporating these genetic gains into the timber supply model, we are essentially shifting up the yield curves and these changes affect the volume of harvestable timber and the AAC. These simulated timber harvests are then used in the spatial equilibrium model to evaluate the economic effects of genomic tree improvement.

\footnotetext{
${ }^{9}$ Forested areas are grouped into categories or strata according to the species that is most dominant in a given area. $\mathrm{C}=$ conifer; $\mathrm{D}=$ deciduous; $\mathrm{CD}=$ conifer leading; $\mathrm{DC}=$ deciduous leading; $\mathrm{Sw}=$ white spruce; $\mathrm{Sb}=$ black spruce; $\mathrm{P}=$ pine; $\mathrm{S}=$ spruce. Therefore, $\mathrm{C}-\mathrm{P}$ indicates a stratum with conifer and pine.

${ }^{10}$ Though AACs are higher than actual harvesting levels since about 2005 due to the approval of increased coniferous AACs to deal with the mountain pine beetle threat (Government of Alberta 2017), timber supply is expected to reduce in Alberta due to mountain pine beetle-induced surge cuts ending and land-based reductions (Schreiber and Thomas 2017). The actual harvesting level and AACs are expected to be close in the near future.
}

The data are compiled from 20 Forest Management Agreement areas in the province, which covers $95 \%$ of the timber production areas in Alberta ${ }^{11}$. Figure 1 shows the initial age class distributions of different species composition strata. Since stands regenerated with improved seeds are projected to grow faster than naturally regenerated stands, the genetic gain is realized through volume gain at rotation. Gains in volume yield are calculated by applying a percent genetic gain to the volume given in the existing provincial yield tables. Figure 2 presents the yield curves for existing stands of different species composition strata. All yield curves are based on harvest volumes from clear-cutting. The data represented by Figs 1 and 2 are used in the timber supply model. The ACEs attributable to the adoption of trees from improved seeds are calculated by repeating the forest level timber supply simulation process under scenarios with and without enhanced growth and yield assumptions. Following Abbott et al. (2009), the lumber recovery rate is assumed to be fixed over time, implying that wood product production changes in parallel with changes in timber supply ${ }^{12}$.

\section{Spatial equilibrium model}

A spatial equilibrium model is calibrated to evaluate the economic effects of SWL supply shifts in Alberta due to genomics-assisted tree breeding and the implementation of the ACE. Specifically, we use the model by Chang and Gaston (2014) which allows us to examine how these changes in Alberta will affect the demand and supply of key timber producing provinces in Canada and key timber producing regions in the rest of the world. Specific details relating to the derivation of net supply and demand as well as the role of positive mathematical programming (Howitt 1995) can be found in Appendix D. The remainder of this section discusses the countries and regions considered and the calculation of the economic benefits.

\section{Countries and regions}

Assuming interconnected competitive markets, the model considers two net demand regions and four net supply regions ${ }^{13}$. Three of the net supply regions are from Canada: Alberta, British Columbia and the rest of Canada (ROC). Alberta is the focus of this study, and British Columbia is the most important SWL producer in Canada. In 2015, British Columbia accounted for $63.4 \%$ of Canadian SWL exports and $25.6 \%$ of global SWL exports (FAO 2015). The remaining export regions are grouped together as one, and denoted the rest of the world export (ROW_ex).

The demand for SWL is dominated by the United States where almost $31.6 \%$ of all foreign exports were destined in 2015 (FAO 2015). In 2015, 94\% of the total United States SWL imports were from Canada. Figure 3 shows the major SWL markets in Alberta. It is obvious that the United States

\footnotetext{
${ }^{11}$ The remaining $5 \%$ could not be assigned to a species composition stratum due to technical issues.

${ }^{12}$ The lumber recovery factor refers to the amount of lumber that can be recovered from a log; it is a measure of lumber yield. It is assumed that this is constant in our analysis.

${ }^{13}$ Since all of our regions both buy and sell timber, we define net demand regions as regions that buy more timber than they sell, while net supply regions are regions that sell more timber than they buy.
} 

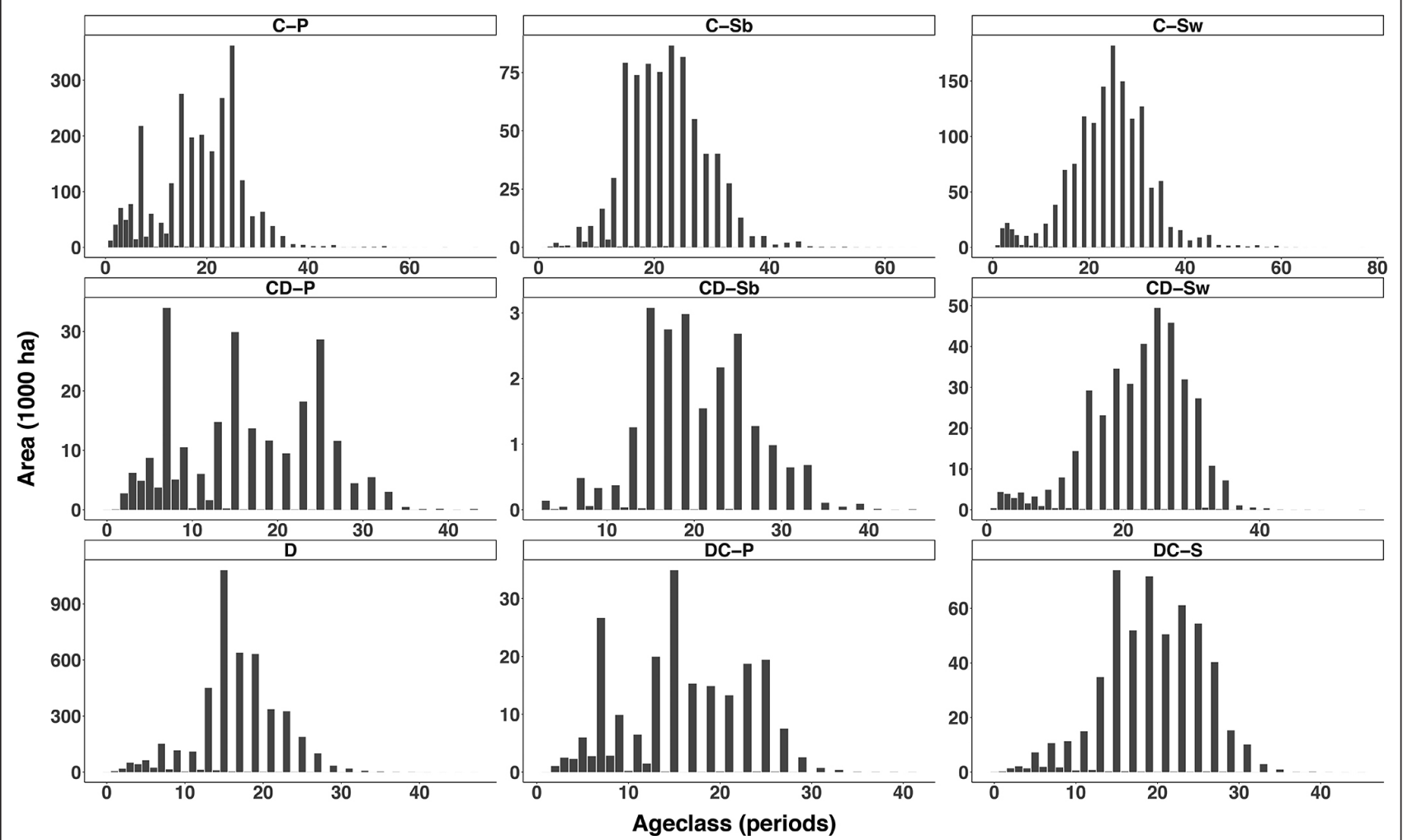

Fig. 1 Starting age class distributions by species composition strata. Age classes are in five-year periods. Each strata is defined as broad cover-type leading species. $C=$ conifer; $D=$ deciduous; $C D=$ conifer leading; $D C=$ deciduous leading; $S w=w h i t e ~ s p r u c e ; ~ S b=$ black spruce; $P$ = pine; $S$ = spruce. Data source: Government of Alberta.

is the single most important trade partner for Alberta with $96 \%$ of total Alberta SWL exports shipped to the United States. One thing to note from Fig. 3 is the decrease in exports to the United States during the early 2000s which was due to a combination of trade policies (e.g., countervailing and antidumping duties), a decrease in new residential housing construction, the financial crisis, and a rising Canadian dollar. The United States is treated as its own import region in this study while the remaining import regions are grouped together and denoted rest of the world import (ROW_im).

Table 1 reports the regional SWL production, consumption, mean price values and elasticity estimates; Table 2 reports the trade flow data between regions. The base-year prices of SWL in each region are derived from the weighted means of the unit values of exports or imports (Chang and Gaston 2014). To define the initial equilibrium of the model, values are assigned for all elasticities as well as initial prices and quantities shown in Eqs (6)-(13) (Appendix D). Positive mathematical programming is used to calibrate the spatial equilibrium model to actual SWL trade flows among trade regions so that the transportation costs represent the shadow price, which considers factors that are not included in the transportation cost (e.g., heterogeneous lumber quality, tariffs, etc.). The equilibrium prices are different in the different regions due to transportation costs, which include all the costs associated with moving lumber between regions and associated transaction costs such as insurance (Chang and
Gaston 2014). The spatial equilibrium model assumes that transportation costs are equal to the difference in prices between two regions (Paris et al. 2011; van Kooten and Johnston 2014). Following Chang and Gaston (2014), the shadow prices generated from the optimal solution are used to adjust the original transportation costs in the objective function so that they represent the "effective" transaction costs between the export and import regions. See Appendix D for more details on the derivation of net supply and demand and the positive mathematical programming model.

\section{Net present value of economic benefits}

A tree genetic improvement program entails a sequence of steps leading to improvements in genetic gain for a given trait over time. Thus, it is important to identify the timing of the supply shock and the timing of the shock's effect. This study estimates the economic effects of increased volume due to genetic improvements over a 38-year period from 2016 to 2053. A 38-year period is used as this is the minimum length of time that allows improved seeds to be produced from both traditional breeding and genomics assisted tree breeding technologies ${ }^{14}$. To arrive at a cumulative estimate of the value

\footnotetext{
${ }^{14}$ We looked at longer horizons but using a longer period would only increase the relative benefits of genomics assisted tree breeding to traditional breeding. Therefore, we decided to use only the results of a 38-year period to be conservative.
} 


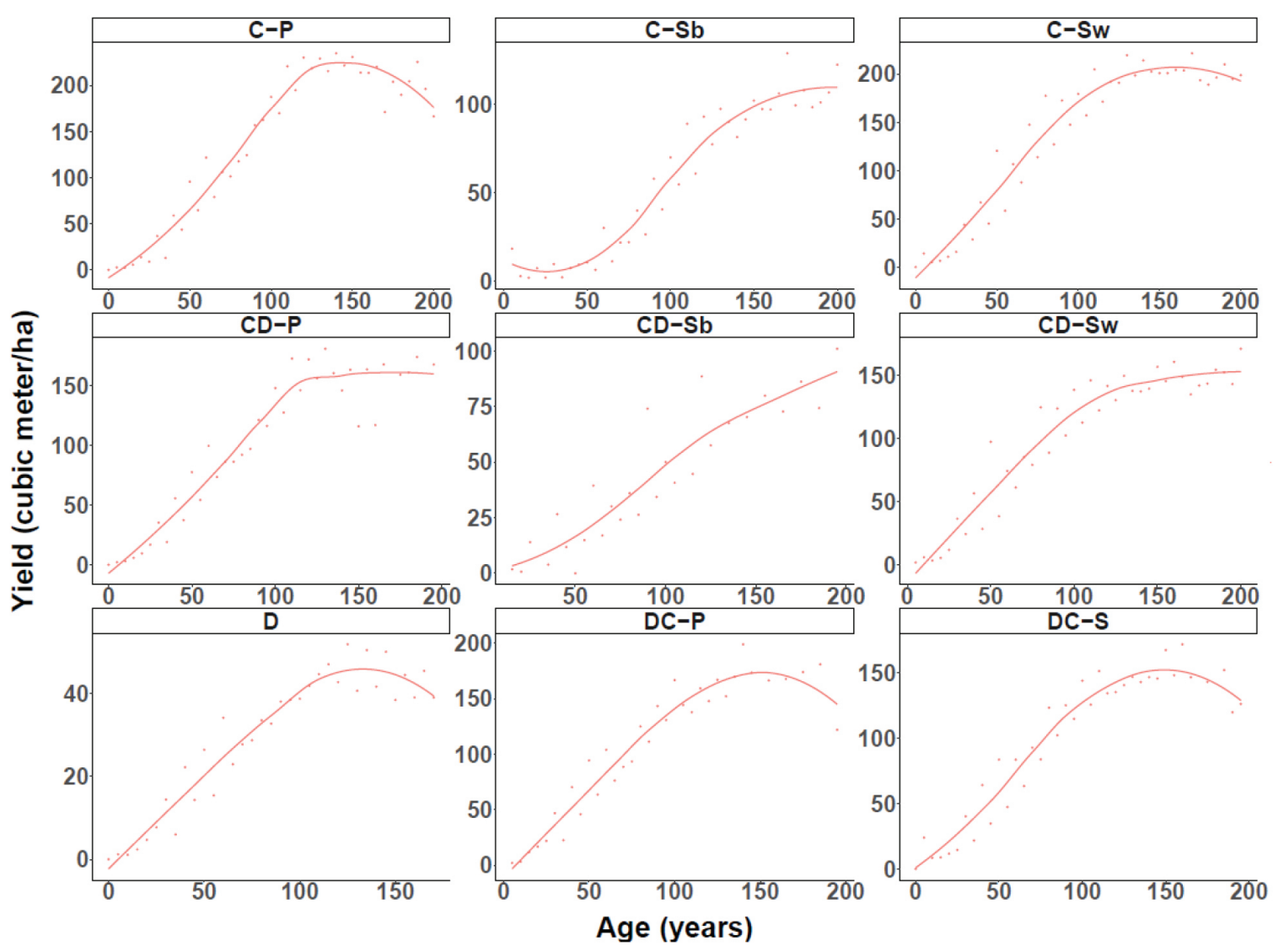

Fig. 2 Yield curves by species composition strata for initial stands. The definition of strata is the same as described in Fig. Data source: Government of Alberta.

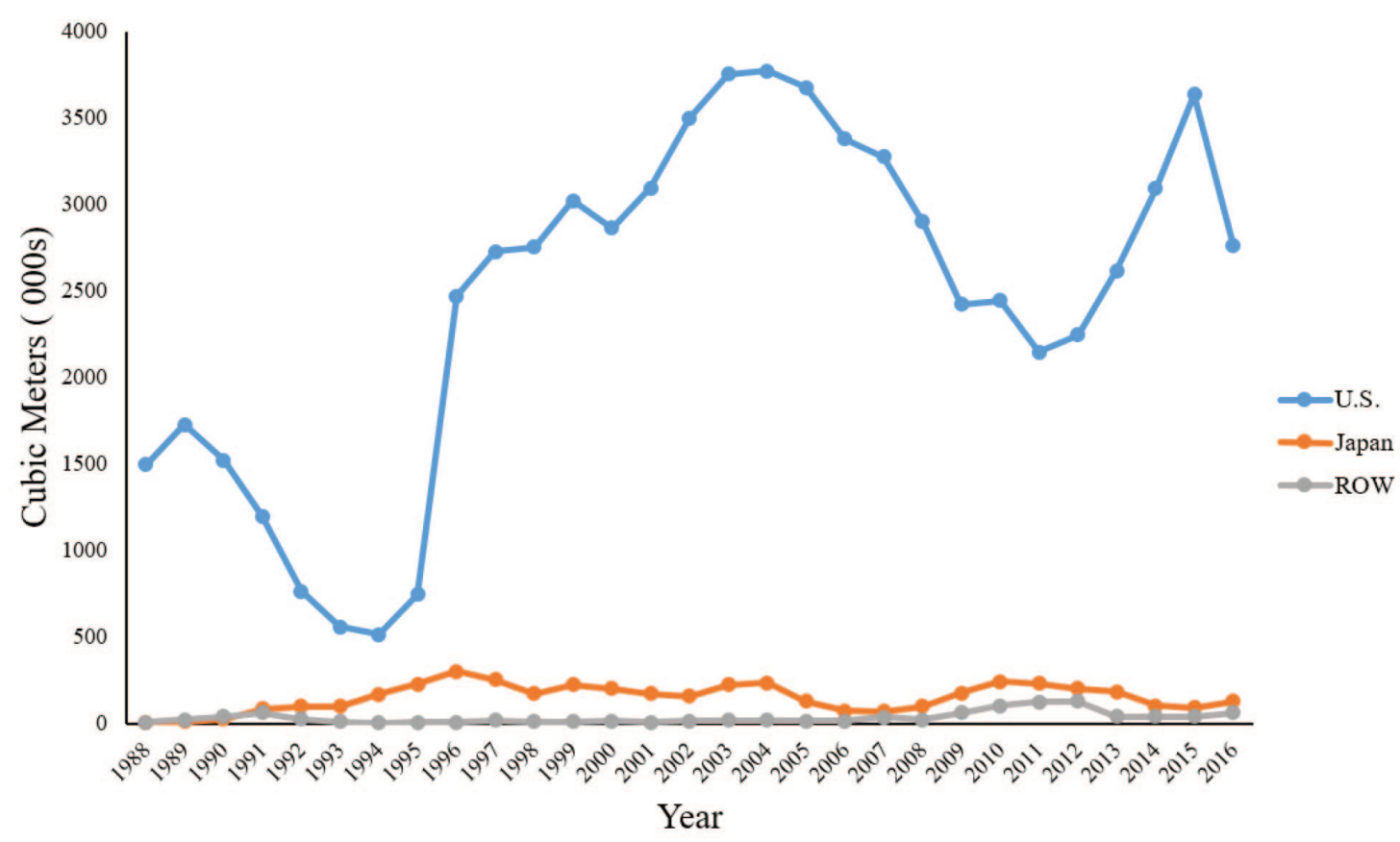

Fig. 3 Alberta softwood lumber exports to major markets, 1988-2016. U.S. refers to the United States and ROW to rest of the world. Data source: Canadian International Merchandise Trade Database. 
Table 1. Regional softwood lumber production, consumption, prices and demand and supply elasticities in base year 2015 used to define the initial equilibrium

\begin{tabular}{|c|c|c|c|c|c|}
\hline Region & $\begin{array}{c}\text { Production } \\
\left(\text { million } \mathbf{m}^{3}\right)\end{array}$ & $\begin{array}{c}\text { Consumption } \\
\left(\text { million } \mathbf{m}^{3}\right)\end{array}$ & $\begin{array}{l}\text { Metric price } \\
\qquad\left(\$ \mathrm{~m}^{-3}\right)\end{array}$ & $\begin{array}{l}\text { Demand } \\
\text { elasticity }\end{array}$ & $\begin{array}{c}\text { Supply } \\
\text { elasticity }\end{array}$ \\
\hline \multicolumn{6}{|c|}{ Net supply regions } \\
\hline $\mathrm{AB}$ & 9.27 & 5.50 & $\$ 171$ & -0.34 & 1 \\
\hline $\mathrm{BC}$ & 31.18 & 4.98 & $\$ 221$ & -0.34 & 1 \\
\hline ROC & 22.53 & 11.14 & $\$ 181$ & -0.34 & 1 \\
\hline ROW_ex ${ }^{a}$ & 101.55 & 40.51 & $\$ 350$ & -0.34 & 1 \\
\hline \multicolumn{6}{|c|}{ Net demand regions } \\
\hline U.S. & 54.34 & 86.70 & $\$ 204$ & -0.34 & 1 \\
\hline ROW_im & 164.71 & 234.74 & $\$ 332$ & -0.34 & 1 \\
\hline
\end{tabular}

Note: The source used for elasticity estimates is from Cardellichio (1989) for all regions. All other information in the table is estimated by the authors using data from FAO (2015) and CANSIM table 3030064 (Statistics Canada 2015b).

ancluding Austria, Chile, Finland, Latvia, New Zealand, Romania, Russian Federation, Sweden, Belarus, Brazil, and Ukraine. AB refers to Alberta; BC refers to British Columbia; U.S. refers to the United States; ROC refers to the rest of Canada; ROW_ex refers to export regions of the rest of the world; and ROW_im refers to import regions of the rest of the world.

Table 2. Product group trade flows in base year 2015 (million $\mathrm{m}^{3}$ )

\begin{tabular}{lrrr}
\hline & \multicolumn{2}{c}{ Import Region } & \\
\cline { 2 - 3 } Export Region & U.S. & ROW_im & Total \\
\hline AB & 3.64 & 0.13 & 3.77 \\
BC & 15.53 & 10.67 & 26.20 \\
ROC & 11.27 & 0.12 & 11.38 \\
ROW_ex & 1.93 & 59.11 & 61.04 \\
\hline Total & $\mathbf{3 2 . 3 6}$ & $\mathbf{7 0 . 0 3}$ & $\mathbf{1 0 2 . 3 9}$ \\
\hline
\end{tabular}

Note: The trade flows in the table were estimated by the authors using data from the Canadian international merchandise trade database (Statistics Canada 2015a) and UN Comtrade database (United Nations 2015). The acronyms of the regions are defined in the footnote of Table 1.

of the research program today, the discounted net economic benefit is calculated for the entire stream of research gains $\left(N P V^{N E B}\right)$, which is the discounted sum of consumers' and producers' surpluses net of R\&D expenditures from 2016 to 2053 (eq. 37) or:

$$
\text { (5) } N P V^{N E B}=\sum_{t=0}^{T}(1+\rho)^{-n}\left(C S_{t}+P S_{t}-E_{t}\right)
$$

where $N P V^{N E B}$ is the net present value of the economic benefits of the research program; $\rho$ is the discount rate; $C S_{t}$ is the value of consumer surplus in year $t ; P S_{t}$ is the value of producer surplus in year $t ; E_{t}$ is the R\&D cost in year $t$.

\section{Simulation scenarios}

In this section, a plausible baseline scenario is first constructed to represent the benchmark counterfactual in which the genomic $\mathrm{R} \& \mathrm{D}$ program does not exist and no improvement from genomics-based technologies arise. Then simulations of the impacts of genomics-assisted tree breeding technologies are conducted. Under each alternative scenario, producer and consumer benefits are computed for each year of the simulation as the change in producer surplus and consumer surplus, relative to the baseline scenario. Annual total benefits are equal to the sum of producer and consumer benefits.

\section{Benchmark scenario}

The benchmark scenario represents economic outcomes given the existing improved seed. The model's ability to analyze alternative scenarios allows for the examination of a variety of different future conditions affecting domestic supply and demand conditions (Delcourt 1995). To project the future supply and demand of SWL, intercepts ${ }^{15}$ of domestic supply and demand curves in each region are exogenously shifted using projections about the annual changes in demand and supply curves based on the historical mean annual change (\%) and expected mean annual change (\%) in the future ${ }^{16}$.

Figure 4 shows the historical SWL production in all regions from 2005 to 2016 . The historical mean annual change is negative in BC $(-2 \%)$, ROC $(-1 \%)$, and the U.S. $(-1 \%)$, but positive in Alberta (2\%), ROW_ex (1\%) and ROW_im (1\%). For ROC, ROW_ex and ROW_im, it is assumed that the annual changes will follow the historical trends for the period 2016-2035. For Alberta, the annual allowable cut has increased in recent years due to new management strategies in regards to the mountain pine beetle infestation. However, in the near future, timber supply is expected to decrease and revert back to pre-mountain pine beetle infestation levels as a result of mountain pine beetle surge cuts ending and land-based reductions (Schreiber and Thomas 2017). Together, these changes lead to a $25 \%$ reduction in timber supply. Thus, it is assumed that SWL supply in Alberta will decrease by 25\% from 2021 to 2035. For BC, a drop in timber supply of $25 \%$ is also expected over the next 20 years due to the mountain pine beetle infestation (BC Ministry of Forests, Lands and Natural Resource Operations 2012). Therefore, the annual reduction in supply for $B C$ is assumed to be $1.25 \%$ from 2016-2035. For the U.S., although

\footnotetext{
${ }^{15}$ There is extensive literature on the types of supply shifts due to innovations (Alston et al. 2009). Parallel shifts are assumed here for simplicity but recognize that this may over-estimate the returns if the actual shift is divergent or pivotal.

${ }^{16}$ If technological change is occurring in these other regions, it could result in higher mean annual changes than expected, based on historical averages. Therefore, the actual benefits (costs) to Alberta may be lower (higher).
} 


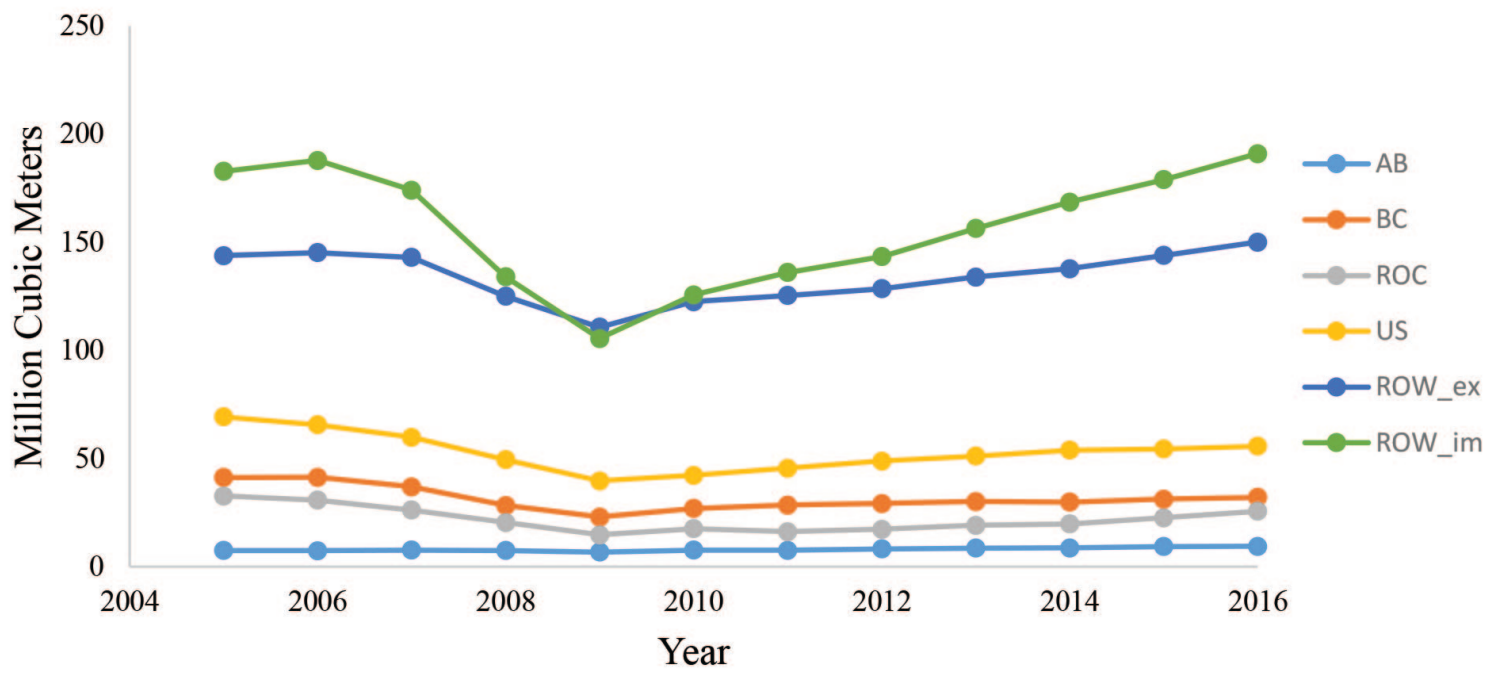

Fig. 4 Historical softwood lumber production by regions, 2005-2016. The acronyms of the regions are defined in the footnote of Table 1.

the figures show that historically the mean annual production change is $-1 \%$, U.S. SWL production is expected to increase in the future due to U.S. export duties imposed on Canadian lumber in 2017 and the increase in plantation forests in the southern United States. Given these countervailing effects, the mean annual change in U.S. SWL production is assumed to be $0 \%$.

Following Chang and Gaston (2014), it is assumed that there is no change in SWL demand in Canada over time. The annual increase in SWL demand for the rest of the world import (ROW_im) and export regions (ROW_ex) is assumed to be $1.5 \%$ due to population increase and economic growth. In the United States, the annual increase in demand of SWL is assumed to be $3 \%$ due to the growing U.S. demand in housing. Since it is very difficult to predict the SWL supply and demand for the period of 2036-2053, it is assumed that the demand and supply are constant until 2036 under the benchmark scenario ${ }^{17}$. Assumptions about future mean annual supply and demand changes (\%) in SWL products for all regions under the benchmark scenario are summarized in Table 3.

\section{Breeding improvement scenarios}

Simulations of the impacts of alternative breeding technologies are conducted for traditional breeding and genomics-assisted tree breeding. These two breeding technologies are charac-

\footnotetext{
${ }^{17}$ Since we are interested in the change of welfare between the benchmark and other genomic scenarios instead of projecting future production and consumption, this approach should be legitimate and it allows us to estimate the effect of supply disturbances caused by genomic technology in isolation.
}

terized by alternative combinations of assumptions about genetic gain, $\mathrm{R} \& \mathrm{D}$ lags and adoption rates (i.e., the proportion of land planted with improved trees). Since genomics research is still developing and the exact effects of the new technology on timber growth and potential lags in commercialization are unknown, scientists conducting the research were interviewed to obtain a deeper understanding of its potential future outcomes. Using these expert opinions, potential pathways of producing $2^{\text {nd }}$ and $3^{\text {rd }}$ generation improved seed to achieve higher growth gain using both traditional breeding and genomics-assisted tree breeding are developed (Appendices A and B). Specifically, in the scenario of producing $2^{\text {nd }}$ generation improved seed, both traditional breeding and genomics-assisted breeding have the same R\&D lag of 18 years (Appendix A). However, as previous studies have demonstrated that genomics-assisted tree breeding can provide more accurate genetic variance components and breeding value estimates than traditional breeding
Table 3. Assumptions for future mean annual supply and demand changes [\%] for softwood lumber production in both import and export regions

\begin{tabular}{|c|c|c|c|c|c|c|}
\hline & \multicolumn{2}{|c|}{ 2016-2020 } & \multicolumn{2}{|c|}{ 2021-2035 } & \multicolumn{2}{|c|}{$2036-2053$} \\
\hline & Demand & Supply & Demand & Supply & Demand & Supply \\
\hline \multicolumn{7}{|c|}{ Net supply regions } \\
\hline $\mathrm{AB}$ & 0 & 0 & 0 & -1.6 & 0 & 0 \\
\hline $\mathrm{BC}$ & 0 & -1.25 & 0 & -1.25 & 0 & 0 \\
\hline ROC & 0 & -1 & 0 & -1 & 0 & 0 \\
\hline ROW_ex & 1.5 & 1 & 1.5 & 1 & 0 & 0 \\
\hline \multicolumn{7}{|c|}{ Net demand regions } \\
\hline U.S. & 3 & 0 & 3 & 0 & 0 & 0 \\
\hline ROW_im & 1.5 & 1 & 1.5 & 1 & 0 & 0 \\
\hline
\end{tabular}

Note: The assumptions are based on data from FAO (2009), British Columbia Ministry of Forests, Lands and Natural Resource Operations (2012), and Chang and Gaston (2014). The acronyms of the regions are defined in the footnote of Table 1. 
Table 4. Elicited parameters for different R\&D scenarios

\begin{tabular}{lccc}
\hline $\begin{array}{l}\text { Breeding } \\
\text { Strategies }\end{array}$ & $\begin{array}{c}\text { Genetic } \\
\text { Volume } \\
\text { Gain (\%) }\end{array}$ & $\begin{array}{c}\text { R\&D Lags } \\
\text { (years) }\end{array}$ & $\begin{array}{c}\text { R\&D Costs } \\
\text { (M \$) }\end{array}$ \\
\hline $2^{\text {nd }}$ Gen. Improved Seeds & & & \\
TB & 15 & 18 & 6.5 \\
GATB & 20 & 18 & 16.4 \\
$3^{\text {rd Gen. Improved Seeds }}$ & & & \\
TB & 25 & 38 & 7.9 \\
GATB & 30 & 23 & 16.3 \\
\hline
\end{tabular}

Note: The assumptions are based on experts' opinions. TB refers to traditional breeding; GATB refers to genomics-assisted tree breeding; Gen. refers to generation. See Appendices A \& B for the specific R\&D process for each scenario.

(El-Kassaby et al. 2012), genomics-assisted tree breeding has higher selection accuracy and allows for a higher level of genetic volume gain. Thus, this scenario examines the higher selection accuracy effect only. In the scenario of producing $3^{\text {rd }}$ generation improved seed compared with traditional breeding, genomics-assisted tree breeding can not only achieve higher genetic volume gain but also shorten the breeding cycle by 16 years (Appendix B). Therefore, this scenario examines the combined effects of higher selection accuracy and a shorter breeding cycle. For both scenarios, it is assumed that the adoption rate is $100 \%$ once the improved seeds are available and that the technology has a $100 \%$ efficacy rate in enhancing yield. The level of genetic volume gain, $\mathrm{R} \& \mathrm{D}$ lag and $\mathrm{R} \& \mathrm{D} \operatorname{cost}^{18}$ are summarized in Table 4.

Two components of costs associated with traditional breeding and genomics-assisted tree breeding research are considered. The first is the research cost, which includes genotyping and/or phenotyping of the training and verification populations and the model development (see Table C1 in Appendix $\mathrm{C}$ for more details on these research costs). The second component is the operational cost of seed production from seed orchards (Table C2). We then calculated the provincial level cost of both components by multiplying the total cost per tree improvement program by 15 because there are currently 15 white spruce and lodgepole pine tree improvement programs in Alberta. While there are some differences in size among the programs, this approach provides a fair approximation of the total cost.

The first breeding strategy (using traditional breeding to produce $2^{\text {nd }}$ generation improved seed) involves pedigree selection costs and seed production costs. There is no phenotyping cost because the first generation testing and phenotyping has already been done (i.e., these data already exist). The second breeding strategy (using genomics-assisted tree breeding to produce $2^{\text {nd }}$ generation improved seed) involves model development, genotyping, and seed production costs. The third breeding strategy (i.e., using traditional breeding to produce $3^{\text {rd }}$ generation improved seed) involves both phenotyping and production costs and seed production costs. The last breeding strategy (using genomics-assisted tree breeding to produce $3^{\text {rd }}$ generation improved seed) involves model development, genotyping, and seed production costs.

\footnotetext{
${ }^{18}$ See Appendix $C$ for detailed R\&D cost information.
}

\section{Results and discussion}

In this section, the timber supply simulation results are presented first. Next, the economic simulation results, which include results of model calibration, model validation, welfare distribution and sensitivity analyses, are reported.

\section{Timber supply simulation}

The main purpose of the timber supply model is to estimate the AAC (as described in the section on the timber supply model), which allows us to calculate the ACE. Table 5 reports the simulated AACs and ACEs for all scenarios. The starting point is the AAC calibrated to the 2015 level. Since the currently available improved seeds have on average a $5 \%$ genetic volume gain at rotation, it is assumed that all forest companies in Alberta adopted these improved seeds since 2018 in the benchmark scenario. This assumption allows us to simplify the analysis but is also plausible, given the nature of current breeding programs.

In 2015, very few improved seeds were used in Alberta. A new directive in Alberta requires that, where artificial reforestation activities are approved to occur, timber disposition holders must use improved seeds made available for sale from approved Controlled Parentage Program (CPP) seed orchards. The first planting season affected by the directive was 2018 (Alberta Agriculture and Forestry 2016a). For the period $2010-2019,29 \%$ of all provincial white spruce plantings and $14 \%$ of pine plantings were carried out with improved seed. In 2019, improved seed represented 65\% of the total white spruce seed and $20 \%$ of the total pine seed used in the province (Pers. Comm. A. Benowicz, Government of Alberta). Thus, it is assumed that currently available improved seeds with $5 \%$ genetic volume gain would be adopted by all forest companies starting in 2018 in the benchmark scenario.

There are eight white spruce programs and seven lodgepole pine programs in the province. Deployment allowed from any seed orchard is associated with a CPP and depends on the cumulative effective population size $(\mathrm{Ne})$ of the crops coming from the orchard. The limit is dependent on three factors: (1) the total area of the species-specific target strata in the CPP region; (2) the density of planting (trees/ha); and, (3) the planned cumulative $\mathrm{Ne}$ of the seedlots. For lower $\mathrm{Ne}$ (i.e., < 30 ) only $25 \%$ of the area in a CPP can be reforested with improved seed, and as the Ne value goes up, the percent area goes up with the possible deployment of $100 \%$ improved seed. As a counter to this, conservation areas are also required (see Appendix 21A in FGRMS, 2016 (Alberta Agriculture and Forestry 2016b) for deployment details). The size of all CPP regions is outlined in Appendix 19 in FGRMS 2016. Each CPP has a fixed and defined area for deployment and range in size from 822072 ha in the Region K1 lodgepole pine CPP to 1965478 ha for the Region A CPP. The range in white spruce varies from 1655448 ha (Region D) to 5201616 ha (Region D1). Therefore, each program has the potential to deploy $100 \%$ of their landbase with improved stock.

As shown in Table 5, all ACEs are positive as mature reserves of old growth stands are available for immediate $\mathrm{AAC}$ increases. As expected, the ACE increases as the level of genetic gain increases. Since a fixed lumber recovery factor over time is assumed, SWL supply has the same percentage change as timber supply. In the benchmark scenario, the ACE results in a 3.8\% increase in SWL supply in 2018. In the 
Table 5. Simulated annual allowable cuts (AACs) and allowable cut effects (ACEs) for all scenarios

\begin{tabular}{|c|c|c|c|c|}
\hline Scenarios & $\operatorname{AAC}\left(\mathbf{M ~ m}^{3}\right)$ & $\operatorname{ACE}\left(M_{\mathbf{m}^{3}}\right)$ & Timber supply change (\%) & SWL supply change (\%) \\
\hline 2015 Calibrated level & 18.5 & 0 & 0 & 0 \\
\hline Benchmark & 19.2 & 0.7 & 3.8 & 3.8 \\
\hline \multicolumn{5}{|c|}{$2^{\text {nd }}$ Gen. Improved Seeds } \\
\hline $\mathrm{TB}$ & 20.7 & 2.2 & 11.9 & 11.9 \\
\hline GATB & 21.3 & 2.8 & 15.1 & 15.1 \\
\hline \multicolumn{5}{|c|}{$3^{\text {rd }}$ Gen. Improved Seeds } \\
\hline $\mathrm{TB}$ & 22.6 & 4.1 & 22.2 & 22.2 \\
\hline GATB & 23.3 & 4.8 & 25.9 & 25.9 \\
\hline
\end{tabular}

Note: Gen. represents generation, TB traditional tree breeding, SWL softwood lumber, GATB genomics-assisted tree breeding.

scenario with the $2^{\text {nd }}$ generation improved seeds, the ACE leads to an $11.9 \%$ increase in SWL supply in 2033 when traditional breeding is adopted, and a $15.1 \%$ increase in 2033 when genomics-assisted tree breeding is adopted. In the scenario with the $3^{\text {rd }}$ generation improved seeds, the ACE results in a $22.2 \%$ increase in SWL supply in 2053 when traditional breeding is adopted and a $25.9 \%$ increase in 2037 when genomics-assisted tree breeding is adopted. The calculated SWL supply changes in Table 5 serve as inputs to shift the SWL supply curves in the economic model.

\section{Economic simulation}

The production, consumption, trade and price levels of 2015 are precisely duplicated using positive mathematical programming (Table D1 in Appendix D). In each scenario, defined in terms of a particular set of assumptions about the R\&D lag and genetic gain of improved seeds, we simulate region-specific production, consumption, price and trade of SWL over a 38-year horizon. The benchmark scenario reflects currently available technology (i.e., currently available improved seeds). These simulations are then repeated allowing for the adoption of genomic technology. Comparing the outcomes between the simulations for a particular scenario versus the benchmark with current technology yields a measure of the effect of the introduction of the new technology. Changes in consumers' and producers' surpluses resulting from the adoption of different improved seeds are calculated for all scenarios.

\section{Model validation}

The validity of the model and its ability to predict SWL market behaviour is checked by comparing the simulated historical SWL exports against the actual historical SWL exports in Alberta over the period 2003-2016. Historical data on SWL production, consumption, exports and imports of all regions for the period of 2003-2016 are first collected. The annual changes of SWL supply and demand in all regions are then calculated based on actual historical data. Lastly, the calculated annual changes are used to shift the demand and supply curves of the calibrated spatial equilibrium model and to derive simulated historical production, consumption, export, and import quantities. Figure 5 presents real historical and model-predicted historical and future values of SWL exports in Alberta that are developed in the process described above using baseline parameter values.

\section{Gross and net economic benefits from adopting traditional} breeding and genomics-assisted tree breeding

Figure 6 shows the net returns to Alberta from adopting different breeding strategies after accounting for R\&D costs. These returns include benefits received by producers and consumers.

These estimates suggest that all breeding strategies are likely to generate positive benefits. In both cases, the economic returns associated with genomics-assisted tree breeding are higher than the economic returns associated with traditional breeding, indicating that the use of genomic technology can generate greater gains. Specifically, if the goal is to produce $2^{\text {nd }}$ generation improved seeds, genomicsassisted tree breeding has the potential to generate an additional \$404.5 million over traditional breeding; if the goal is to produce $3^{\text {rd }}$ generation improved seeds, genomics-assisted tree breeding has the potential to generate an additional \$2.04 billion over traditional breeding. The additional benefits in the first case ( $2^{\text {nd }}$ generation improved seeds) are lower because there is only a higher selection accuracy effect from genomicsassisted tree breeding versus traditional breeding since the $\mathrm{R} \& \mathrm{D}$ lags are the same for traditional breeding and genomicsassisted tree breeding (18 years). The additional benefits in the second case ( $3^{\text {rd }}$ generation improved seeds) are significantly higher because there is not only a higher selection accuracy effect but also a reduction of 16 years in the R\&D lag time associated with genomics-assisted tree breeding. Therefore, the main driving factor of the additional benefit is the time saved during the breeding process instead of the higher selection accuracy effect in this case. While $2^{\text {nd }}$ generation improved seeds produced using traditional breeding have lower genetic gain than the $3^{\text {rd }}$ generation improved seeds created using traditional breeding $(15 \%<25 \%)$, the net returns from the $2^{\text {nd }}$ generation traditional breeding research are significantly higher than the returns from the $3^{\text {rd }}$ generation traditional breeding research (nearly $\$ 1$ billion versus $\$ 82.6$ million). This is because it takes an additional 16 years to develop the $3^{\text {rd }}$ generation improved seeds and the economic returns are highly discounted over time. This result starkly illustrates the economic benefits of a shorter breeding cycle. 


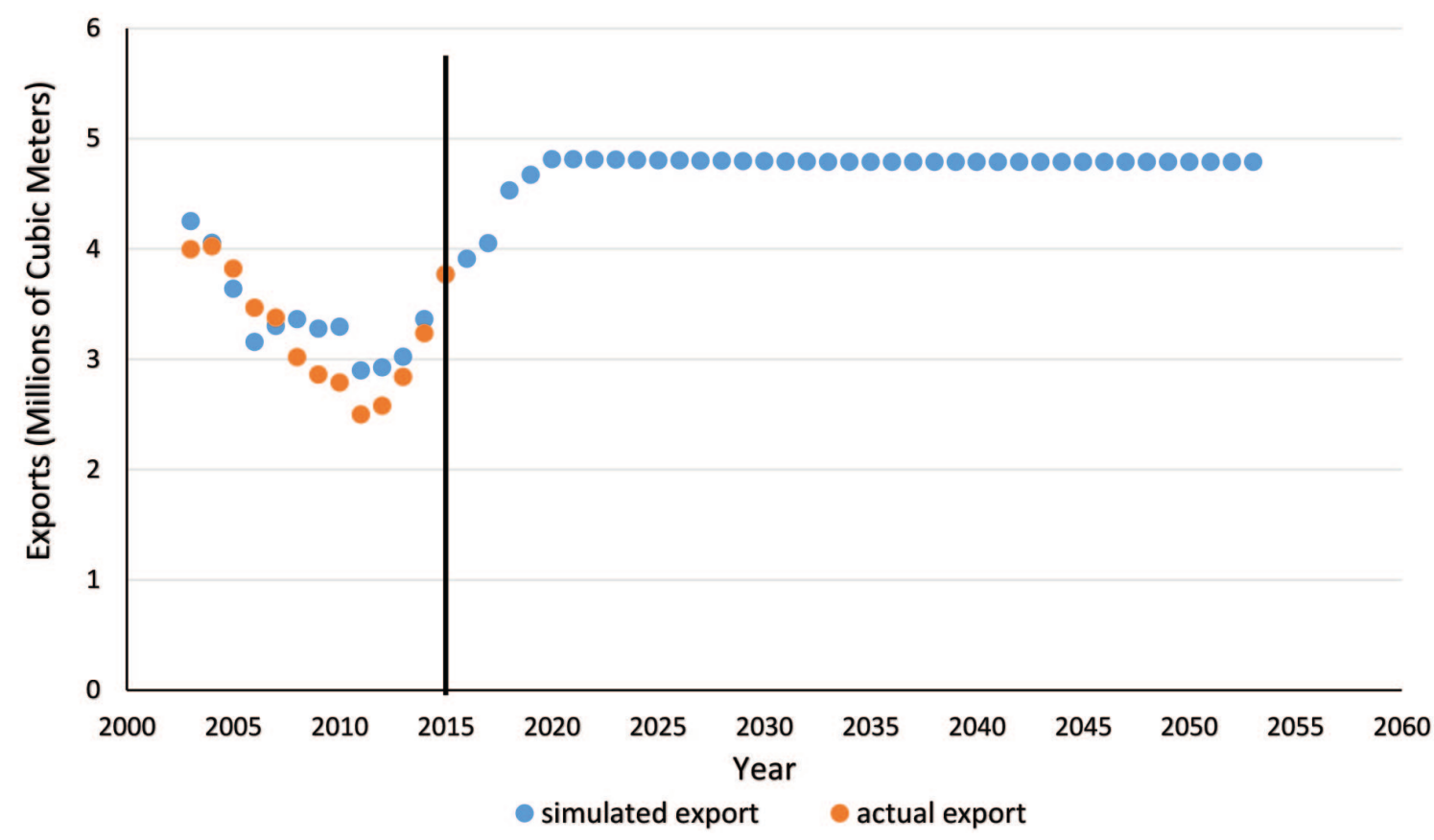

Fig. 5 Simulated and historical softwood lumber exports in Alberta. Mean square error $=8.3 \%$.

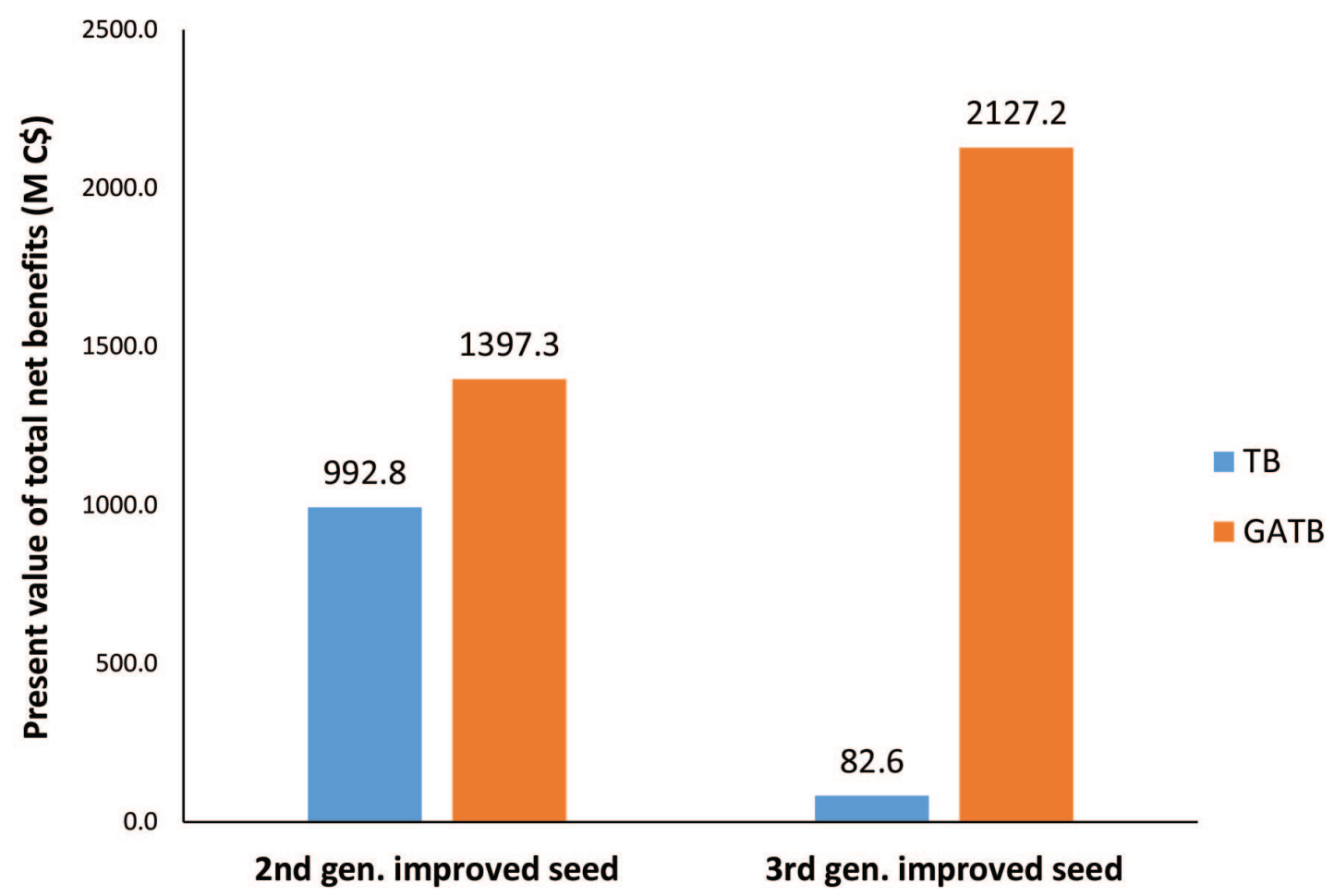

Fig. 6 Present value of total net benefits in Alberta from 2016 to 2053, $r=4 \%$. The R\&D lag is 18 years for all $2^{\text {nd }}$ generation seeds, 38 years for $3^{\text {rd }}$ generation TB, and 23 years for $3^{\text {rd }}$ generation GATB. TB refers to traditional breeding, GATB to genomics-assisted tree breeding. Gen. refers to generation. 
Welfare effects of using traditional breeding and genomicsassisted tree breeding to produce $2^{\text {nd }}$ generation improved seed Table 6 shows the discounted average annual changes in consumer surplus, producer surplus, and total benefits of using $2^{\text {nd }}$ generation improved seeds for reforestation, compared with the benchmark scenario. The measures of changes in economic surplus are expressed as annual averages of discounted changes (using a real discount rate of $4 \%$ per annum) over a 38-year horizon in constant 2015 dollar values. These results are discussed in more detail below.

In most of the regions, the annual change in producer surplus is negative, representing a net loss. However, in the technology adoption region (Alberta), the new technology yields a benefit to producers. This is because the SWL supply increase in Alberta brings the equilibrium price down and regions without yield gains from the technology are therefore worse off. Across all regions, the annual change in consumer surplus is positive. Thus all consumers of SWL experience net gains when supply increases and price decreases. The net benefit is the sum of consumers' and producers' surpluses, which is positive for Alberta, the United States and ROW_im, but negative for British Columbia, the ROC and ROW_ex. In the case of the import regions (U.S. and ROW_im), producer surplus losses are outweighed by consumer surplus gains. However, in other regions where producers also experience a loss (British Columbia, ROC, ROW_ex), the gain in consumer surplus cannot compensate for the loss in producer surplus, resulting in a net loss in those regions. In Alberta, the adoption of genomics-assisted tree breeding yields significantly higher economic benefits than the use of traditional breeding. With traditional breeding, the net benefit is projected to be $\$ 76.68$ million, smaller than the economic benefits of genomics-assisted tree breeding (\$108.46 million).

Though many of the regions experience a loss in producer surplus, the impacts are negligible in relative terms. Table 7 (a) presents the projected mean annual percentage change in production, consumption, trade, price and welfare in all regions when traditional breeding is adopted, while Table 7(b) shows the counterpart measures when genomicsassisted tree breeding is adopted. It is obvious that, with the exception of the significant effects on Alberta, the adoption of genomic technology in Alberta plays a minor role in global SWL markets. The mean annual effects on production, consumption, trade, price, consumer surplus, producer surplus and total surplus are less than $0.4 \%$ in all regions except Alberta. This is because Alberta only produces about $2 \%$ of the world's SWL, and therefore, the increased supply of Alberta SWL will only affect the price marginally over time. Based on the same reasoning, the gain in producer surplus is significantly larger than the gain in consumer surplus in Alberta. Thus, in a competitive SWL market, Alberta producers can act almost as price takers and enjoy the benefits from the increasing timber supply and SWL production.

Welfare effects of using traditional breeding and genomicsassisted tree breeding to produce $3^{\text {rd }}$ generation improved seed Table 8 shows the discounted annual average economic benefits of using the $3^{\text {rd }}$ generation improved seed produced by traditional breeding and genomics-assisted tree breeding for reforestation. In this $3^{\text {rd }}$ generation improved seed scenario, the annual average (discounted) total benefit of genomicsassisted tree breeding is almost 30 times higher than the benefits generated by the traditional breeding approach. This is because genomics-assisted tree breeding results in a higher genetic gain due to the higher selection accuracy effect as well as saving 16 years in $\mathrm{R} \& \mathrm{D}$ time compared with traditional breeding (Grattapaglia et al. 2018). Therefore, to produce the $3^{\text {rd }}$ generation improved seed, it is beneficial to adopt genomics-assisted tree breeding. Similar to the previous results, if improved seed produced using traditional breeding and genomics-assisted tree breeding are used in Alberta, consumers in all regions and Alberta producers are better-off while producers in other regions are worse-off, and the supply shock in Alberta has a negligible impact on other regions.

\section{Sensitivity analysis}

The extent to which the genetic volume gain can be transferred depends on how the government implements the ACE. For example, even if the genetic gain achieved using genomics-assisted tree breeding is 30\%, the government may only allow for a $10 \%$ genetic gain-or one-third of the total gain-to be transferred into the ACE, and therefore the actual increase in timber supply may be less than expected. To address this concern, we conducted a sensitivity analyses around the level of genetic gain that will be transferred into the ACE based on the last two breeding strategies described (i.e., using traditional breeding and genomics-assisted tree breeding to produce the $3^{\text {rd }}$ generation improved seeds).

Table 6. Present value of benefits from using $2^{\text {nd }}$ generation improved seeds, relative to the benchmark scenario (millions of $\$$ )

TB GATB

Changes in PS Changes in CS Total benefit Changes in PS Changes in CS Total benefit

Annual Average Discounted Benefits, 2016-2053

$\begin{array}{lrrrrrr}\text { AB } & 25.91 & 0.39 & 26.30 & 36.66 & 0.54 & 37.20 \\ \text { BC } & -2.30 & 0.36 & -1.94 & -3.2 & -2.70 \\ \text { ROC } & -1.82 & 0.79 & -1.03 & -2.54 & -1.43 \\ \text { ROW_ex } & -10.41 & 3.94 & -6.47 & -14.52 & -11 & -9.49 \\ \text { U.S. } & -5.11 & 10.22 & 5.11 & -7.13 & 14.26 \\ \text { ROW_im } & -18.04 & 22.78 & 4.73 & -25.17 & 31.78\end{array}$

Note: The total benefit is the sum of changes in consumers' and producers' surpluses. PS refers to producer surplus and CS to consumer surplus. All values are expressed in 2015 dollars using a real discount rate of $4 \%$ per annum. The acronyms of the regions are defined in the footnote of Table 1. 
Table 7. Projected mean annual changes [\%] in production, consumption, trade quantities, prices and welfare, relative to the benchmark scenario

\begin{tabular}{|c|c|c|c|c|c|c|c|}
\hline Region & Production & Consumption & Trade & Price & Consumer Surplus & Producer Surplus & Total Surplus \\
\hline \multicolumn{8}{|c|}{ TB with an 18-year ReD lag and 15\% genetic gain, 2016-2053 } \\
\hline $\mathrm{AB}$ & 2.83 & 0.03 & 5.78 & -0.07 & 0.07 & 5.75 & 2.53 \\
\hline $\mathrm{BC}$ & -0.07 & 0.03 & -0.09 & -0.06 & 0.05 & -0.15 & -0.09 \\
\hline $\mathrm{ROC}$ & -0.08 & 0.03 & -0.17 & -0.07 & 0.06 & -0.17 & -0.04 \\
\hline ROW_ex & -0.03 & 0.01 & -0.06 & -0.04 & 0.02 & -0.07 & -0.02 \\
\hline U.S. & -0.06 & 0.02 & 0.11 & -0.06 & 0.04 & -0.13 & 0.02 \\
\hline ROW_im & -0.03 & 0.01 & 0.19 & -0.04 & 0.03 & -0.07 & 0.00 \\
\hline \multicolumn{8}{|c|}{ GATB with an 18-year R\&D lag and 20\% genetic gain, 2016-2053 } \\
\hline $\mathrm{AB}$ & 5.73 & 0.07 & 11.66 & -0.15 & 0.14 & 12.05 & 5.32 \\
\hline $\mathrm{BC}$ & -0.15 & 0.05 & -0.19 & -0.12 & 0.10 & -0.30 & -0.17 \\
\hline ROC & -0.17 & 0.06 & -0.34 & -0.14 & 0.13 & -0.33 & -0.09 \\
\hline ROW_ex & -0.07 & 0.02 & -0.12 & -0.08 & 0.05 & -0.14 & -0.04 \\
\hline U.S. & -0.13 & 0.03 & 0.20 & -0.13 & 0.07 & -0.25 & 0.03 \\
\hline ROW_im & -0.07 & 0.03 & 0.38 & -0.08 & 0.05 & -0.13 & 0.01 \\
\hline
\end{tabular}

Note: The acronyms of the regions are defined in the footnote of Table 1

Table 8. Benefits from using $3^{\text {rd }}$ generation improved seeds, relative to the benchmark scenario (millions of \$)

\begin{tabular}{|c|c|c|c|c|c|c|}
\hline & $\begin{array}{c}\text { TB } \\
\text { Changes in PS }\end{array}$ & $\begin{array}{c}\text { GATB } \\
\text { Changes in CS }\end{array}$ & Total benefit & Changes in PS & Changes in CS & Total benefit \\
\hline \multicolumn{7}{|c|}{ Annual Average Discounted Benefits, 2016-2053 } \\
\hline $\mathrm{AB}$ & 1.92 & 0.03 & 1.95 & 55.62 & 0.79 & 56.41 \\
\hline $\mathrm{BC}$ & -0.16 & 0.03 & -0.14 & -4.63 & 0.73 & -3.91 \\
\hline ROC & -0.13 & 0.06 & -0.07 & -3.68 & 1.60 & -2.08 \\
\hline ROW_ex & -0.74 & 0.28 & -0.46 & -21.09 & 7.98 & -13.11 \\
\hline U.S. & -0.36 & 0.73 & 0.37 & -10.34 & 20.75 & 10.40 \\
\hline ROW_im & -1.29 & 1.62 & 0.34 & -36.58 & 46.17 & 9.59 \\
\hline
\end{tabular}

Note: The total benefit is the sum of changes in consumers' and producers' surpluses. All values are expressed in 2015 dollars using a real discount rate of $4 \%$ per annum. The acronyms of the regions are defined in the footnote of Table 1.

As expected, the higher the level of genetic volume gain that can be transferred into the ACE, the higher the economic returns to traditional breeding and genomics-assisted tree breeding research (Fig. 7). Since the R\&D costs of traditional breeding and genomics-assisted tree breeding are fixed no matter what the level of genetic gain is, the net returns are increasing at a faster rate as the level of genetic gain increases. At all levels of genetic gain, genomics-assisted tree breeding generates significantly more economic benefit than traditional breeding (Fig. 7). The range of the expected net returns for the genomics-assisted tree breeding research is $\$ 126.0$ million to $\$ 2.13$ billion. That means even if only a $6 \%$ genetic gain can be transferred into an ACE, there is a positive (discounted) net benefit of $\$ 126$ million to Alberta across all pine and spruce programs. However, in the case of traditional breeding research, if only a $6 \%$ genetic gain can be transferred into the ACE, the economic benefits are unable to offset the $R \& D$ costs of traditional breeding and the net present value of total benefits is - $\$ 2$ million. In the case of traditional breeding, even if a $30 \%$ genetic gain can be transferred into the ACE, the net present value of total benefits is still lower than the minimum amount of expected economic benefits in the case of genomics-assisted tree breeding when only a $6 \%$ genetic gain can be transferred into the ACE ( $\$ 83$ million $<\$ 126$ million). This finding again indicates that the main driving factor of the economic benefits is the time saved during the breeding process instead of the level of genetic gain. By assumption, the R\&D investment time of genomicsassisted tree breeding is 16 years shorter than the $R \& D$ investment time required by traditional breeding. The results imply that the economic benefits associated with traditional breeding are highly discounted over the decades-long R\&D process while genomics-assisted tree breeding can capture more benefits due to its shorter breeding cycle.

Other uncertain factors, such as the deployment area of improved seeds, can also significantly affect the economic surplus results. To gauge the potential effect of the adoption rate on the economic returns, we also conducted a sensitivity analysis around alternative adoption rates of improved seeds and levels of genetic volume gain. This sensitivity analysis is based on the last breeding strategy (i.e., adopting genomicsassisted tree breeding to produce the $3^{\text {rd }}$ generation improved seeds) as previous results show that this breeding strategy generates the highest returns.

As shown in Table 9, the magnitudes of the economic benefits are sensitive to both the adoption rate and genetic gain levels. In present value terms, the estimates of returns to R\&D from genomics-assisted tree breeding range from $\$-222$ million ( $10 \%$ adoption rate and $6 \%$ genetic gain) to $\$ 2.13$ billion (100\% adoption rate and $30 \%$ genetic gain). Even assum- 


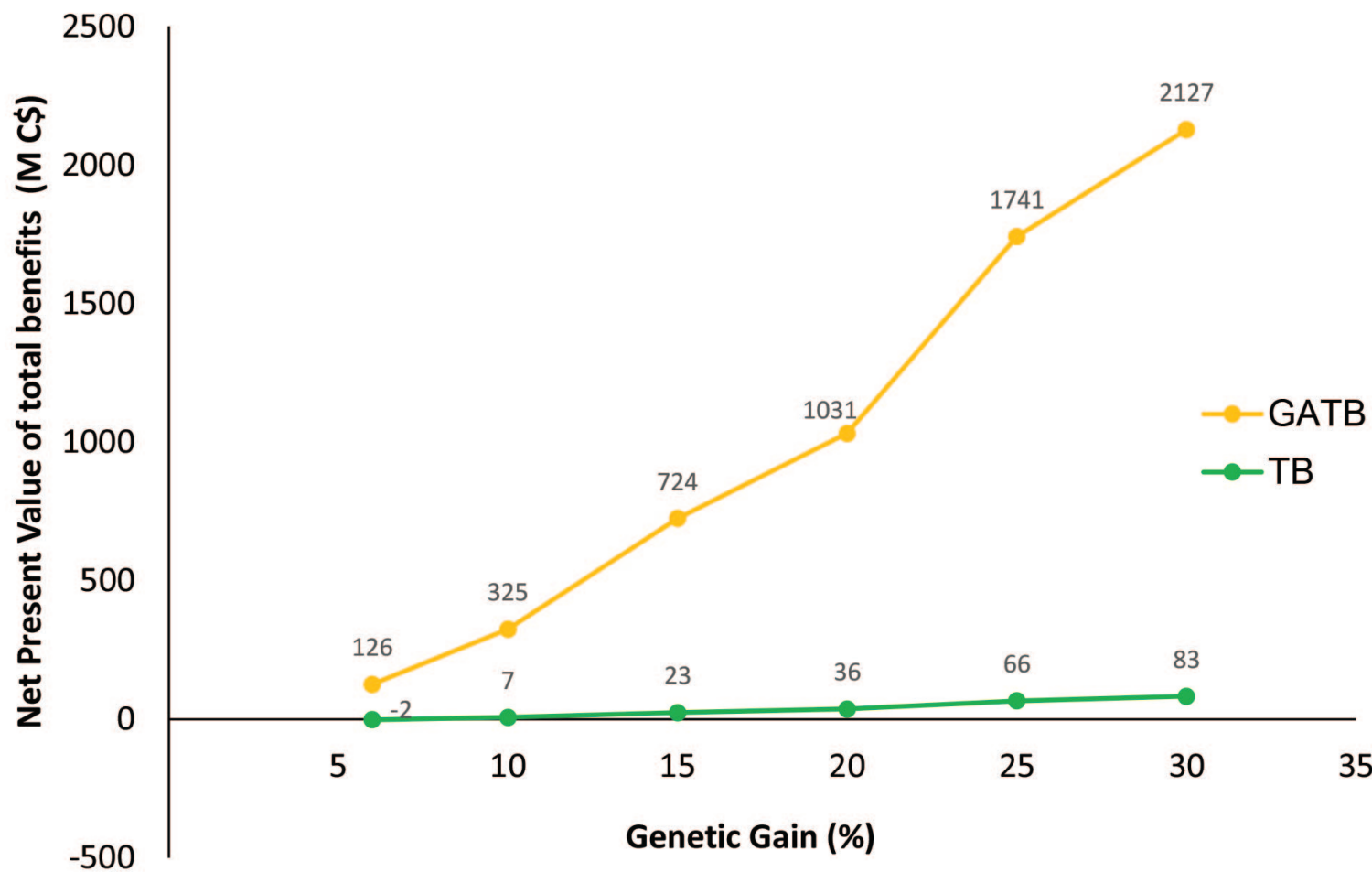

Fig. 7 Net present value of total benefits of $3^{\text {rd }}$ generation improved seeds produced by TB and GATB as the allowable cut effect (genetic gain) varies (discount rate $=4 \%$ ). TB refers to traditional tree breeding; GATB refers to genomics-assisted tree breeding.

ing an optimistic genetic gain of 30\% (with all the gain transferred into the ACE), the sum of discounted returns can still be negative if the adoption rate is below $20 \%$. Moreover, if the genetic gain or the amount of the genetic gain that is transferred into the ACE is lower, then the results suggest that genomics-assisted tree breeding may not yield a positive return. Positive returns are more likely to be positive-even at low genetic volume gains-as long as the adoption rate is $40 \%$ or greater. As of 2014 , approximately 80800 ha in Alberta have been planted with improved pine and spruce seedlings, which represents roughly $15 \%$ of all provincial reforestation. While this number is expected to increase dramatically due to a new provincial seed use policy whose directive is the mandatory use of improved seeds for reforestation (as part of the Controlled Parentage Program), it illustrates the challenge of reaching an adoption rate greater than $40 \%$.

\section{Conclusions}

Research in traditional breeding and genomics-assisted tree breeding produces improved seed with higher genetic volume gain at rotation. In Alberta, the genetic volume gain of improved seed can be transferred into an ACE which allows forest companies to harvest more timber immediately, (assuming old growth forests are available to harvest), even though the actual increase in forest yield will occur in the future. Together, these shifts in timber and SWL supply will have welfare implications for consumers and producers in Alberta. In this study, (1) a timber supply model was con- structed to simulate the ACEs associated with different breeding technologies; and, (2) a recursive spatial equilibrium model was estimated to examine the welfare effects associated with the ACEs. A baseline forecast for the period 2016-2053 was then projected and compared with four alternative scenarios: (1) using traditional breeding to produce $2^{\text {nd }}$ generation improved seeds; (2) using genomics-assisted tree breeding to produce $2^{\text {nd }}$ generation improved seeds; (3) using traditional breeding to produce $3^{\text {rd }}$ generation improved seeds; and, (4) using genomics-assisted tree breeding to produce $3^{\text {rd }}$ generation improved seeds. A comparison of the simulated scenarios with the baseline projection reveals the economic benefits due to traditional breeding and genomics-assisted tree breeding research.

The results show that it can be economically beneficial to use the ACE policy instrument to encourage investment in tree improvement in Alberta because the simulated ACEs in all breeding scenarios are positive and therefore lead to positive economic returns above certain volume gain and adoption rate thresholds. Using genomics-assisted tree breeding is also found to produce the $3^{\text {rd }}$ generation improved seed that generates the highest economic returns due to the existence of both a higher selection accuracy effect and a shorter breeding cycle effect. The sensitivity analysis results indicate that the main driving factor of the economic returns is the time saved during the breeding process. The main conclusion drawn from this study is that integrating genomic technology into current tree improvement programs has the potential to be beneficial but the size of this benefit is greatly influenced 
Table 9. Discounted economic returns (millions of \$) of adopting GATB to produce $3^{\text {rd }}$ generation improved seeds as the deployment area and the level of genetic gain varies

\begin{tabular}{lcccccc}
\hline & \multicolumn{7}{c}{ Genetic Volume Gain at Rotation (\%) } \\
\cline { 2 - 7 } Adoption Rate & $\mathbf{6}$ & $\mathbf{1 0}$ & $\mathbf{1 5}$ & $\mathbf{2 0}$ & $\mathbf{2 5}$ & $\mathbf{3 0}$ \\
\hline 100 & 126 & 325 & 724 & 1031 & 1741 & 2127 \\
80 & 28 & 171 & 518 & 677 & 1197 & 1516 \\
60 & -16 & 28 & 325 & 416 & 724 & 983 \\
40 & -113 & -69 & 126 & 225 & 325 & 472 \\
20 & -184 & -146 & -65 & -59 & -2 & 3 \\
15 & -203 & -161 & -112 & -93 & -73 & -39 \\
10 & -222 & -173 & -159 & -145 & -139 & -103 \\
\hline
\end{tabular}

Note: Adoption rate refers to the percentage of total reforestation area in Alberta that is deployed with $3^{\text {rd }}$ generation improved seeds produced using GATB. All values are expressed in real 2015 dollars. Values are discounted to 2015 present values using a real discount rate of $4 \%$ per annum.

by the actual genetic gain and government policy. If the government decides not to approve an ACE or only approves a small proportion of the genetic volume gain, the economic benefits associated with genomics-assisted tree breeding will likely be unable to offset the higher R\&D costs.

There are several limitations associated with this ex ante analysis of the economic impact of adopting genomicsassisted tree breeding. First and foremost, it is assumed that the genomic technology is yield-enhancing with certainty and our study is based on expected genetic volume gain as the genomics R\&D is ongoing and the actual volume gain is unknown. To increase the accuracy of the results, an expost assessment should be done once the efficacy of the genomic technology has been tested in the field. Second, due to a lack of spatial forest inventory data, the timber supply analysis and the calculation of the ACE are simplified using provincial level non-spatial forest inventory data. A study that is at the forest management area level and uses spatial forest inventory data would be more informative. Third, the effect of timber processing capacity limitations on supply behaviour is not captured. Future studies could address this issue by incorporating the capacity constraints of mills into the model. Fourth, only a volume gain is considered as a result of tree improvement programs and other changes associated with the use of genomic technology are ignored. Specifically, there may be quantity-quality tradeoffs that may reduce the total economic benefits.

The results of this study have a number of important implications. First, it is beneficial for forest companies to replace current traditional breeding techniques with genomics-assisted tree breeding because the economic returns are higher than traditional breeding in all cases (Tables 7 and 8), even though the difference is small and even negative when the government approves little or no genetic gain through ACE. Traditional breeding requires decadelong phenotyping for each cycle of breeding leading to higher risks, costs and greater uncertainty. Genomic technology can be seen as a powerful tool to overcome this challenge as genomics-assisted tree breeding does not require phenotyping after the first breeding cycle, and therefore can shorten the breeding cycle by up to 20 years in cycle two and possibly cycle three of a given tree improvement program.

Second, the Alberta government may want to provide greater flexibility to forest companies to encourage technical change and maintain competitiveness in the forest sector.
While the government intends to use the ACE as a policy instrument to encourage private investments in silviculture activities, the actual effects of the ACE have not been significant in the past. The results of this study show that there are potentially large economic benefits associated with the ACE policy, indicating that there is room for the Alberta government to adjust the use of the ACE policy so that forest companies have more incentives to adopt new technologies and the forest sector can be better off relative to the status quo.

\section{Acknowledgements}

We acknowledge cash funding for this research from Genome Canada, Genome Alberta through Alberta Economic Trade and Development, Genome British Columbia, the University of Alberta and the University of Calgary. Further cash funding has been provided by Alberta Innovates BioSolutions, Forest Resource Improvement Association of Alberta, and the Forest Resource Improvement Program through West Fraser Ltd. (Blue Ridge Lumber and HintonvWood Products) and Weyerhaeuser Timberlands (Grande Prairie and Pembina). In-kind funding has been provided by Alberta Agriculture and Forestry, Blue Ridge Lumber West Fraser, Weyerhaeuser Timberlands Grande Prairie, and the Thomas, Wishart and Erbilgin labs in support of the Resilient Forests (RES-FOR): Climate, Pests \&amp; Policy - Genomic Applications project.

\section{References}

Abbott, B., B. Stennes and G. Cornelis van Kooten. 2009. Mountain pine beetle, global markets, and the British Columbia forest economy. Can. J. For. Res. 39 (7): 1313-1321.

Adams, D. M. and R. W. Haynes. 1987. The global forest sector: An analytical perspective. In: M. Kallio, D. P. Dykstra, \& C. S. Binkley (Eds.). The global forest sector: An analytical perspective (pp. 391413). Chichester [West Sussex]; New York: Wiley.

Alberta Agriculture and Forestry. 2016a. Directive: Mandatory use of improved seed for reforestation [online]. Available from: https://open.alberta.ca/publications/aaf-forestry-policy-2016-noaf-fp-2016-02.

Alberta Agriculture and Forestry. 2016b. Alberta Forest Genetic Resource Management and Conservation Standards (FGRMS). Volume 1: Stream 1 and Stream 2 [online]. Alberta Agriculture and Forestry. Available from: https://open.alberta.ca/dataset/871d9683824b-468f-9ab1-f2c3e3da3513/resource/8d39c2df-48aa-43d9-83a1-ad 747f24ee2e/download/af-fgrms-stream1-2-version-july-2020.pdf 
Alberta Agriculture and Forestry. 2017. Alberta Wood Products [online]. Alberta Agriculture and Forestry. Available from: http://www.albertawoodproducts.ca/.

Alberta Agriculture and Forestry. 2018. Forest Tenure-Forest Management [online]. Available from:https://www.agric.gov.ab.ca/ app $21 /$ forestrypage? cat $1=$ Forest $\% 20$ Management $\&$ cat $2=$ Forest $\%$ 20Tenure.

Alston, J., P. Pardey, J. James and M. Andersen. 2009. The economics of agricultural R\&D. Ann. Rev. Res. Econ. 1: 537-566.

Anderson, J. A., G. W. Armstrong, M. K. Luckert and W. L. Adamowicz. 2012. Optimal zoning of forested land considering the contribution of exotic plantations. Math. Comput. Forestry Nat. Res. Sci. 4 (2): 92.

BC Ministry of Forests, Lands and Natural Resource Operation. 2012. BC's mountain pine beetle epidemic current status and projections. Presentation for special committee on timber supply. Available from: https://www.leg.bc.ca/content/legacy/web/ $\mathrm{cmt} / 39$ thparl/session-4/timber/ reports/PDF/Rpt-TIMBER-394-GrowingFibreGrowingValue-2012-AUG-15.pdf.

Byram, T. D., T. J. Mullin, T. L. White and J. P. van Buijtenen. 2005. The future of tree improvement in the Southeastern United States: Alternative visions for the next decade. South. J. Appl. For. 29 (2): 88-95.

Cardellichio, P. A. 1989. Preliminary analysis of timber and timber products production, consumption, trade, and prices in the Pacific Rim until 2000. CINTRAFOR, College of Forest Resources, University of Washington, WA.

Chang, W.-Y. and C. Gaston. 2014. The competitiveness of Canadian softwood lumber: A disaggregated trade-flow analysis. Can. J. For. Res. 44(12): 1494-1506.

Chang, W.-Y. and C. Gaston. 2015. A trade flow analysis of the global softwood log market: Implications of Russian log export tax reduction and New Zealand log production restriction. J. For. Res. 89 (1): 20-35.

Chang, W.-Y., S. Wang, C. Gaston, J. Cool, H. An and B. R. Thomas. 2019. Economic evaluation of tree improvement for planted forests: A systematic review. BioBus 4 (1), 1-14.

Delcourt, G. V. 1995. Global softwood lumber trade: A spatial equilibrium model [PhD Thesis]. University of British Columbia.

El-Kassaby, Y. A., J. Kl' ap ${ }^{`}$ st $^{\vee} \mathrm{e}$ and R. D. Guy. 2012. Breeding without breeding: Selection using the genomic best linear unbiased predictor method (GBLUP). New Forests 43 (5-6): 631-637.

FAO. 2015. Forestry Production and Trade [online]. Food and Agriculture Orginazition of the United Nations. Available from: http://www.fao.org/ faostat/en/\#data/FO.

Gaston, C. and M. Marinescu. 2006. The competitiveness of Canadian softwood lumber- a trade flow analysis. Forintek Canada Corp., Vancouver, British Columbia, Research Paper W-2270.

Genome Canada. 2017. Genome Financial Reporting System. Available from: http://genomereports.ca/section.php?Lang= En\&ID $=3 \& N a v=$ Section.

Government of Alberta. 2006. Alberta Forest Management Planning Standard [online]. Available from: https://open.alberta.ca/ publications/3491799.

Government of Alberta. 2016. Alberta timber harvest planning and operating ground rules framework for renewal [online]. Available from: https://www1.agric.gov.ab.ca/\$department/deptdocs.nsf/all/ formain 15749/\$FILE/ TimberHarvestPlanning-OperatingGround RulesFramework-Dec2016.pdf.

Government of Alberta. 2017. Sustainable forest management facts \& statistics: Forest management plans. Technical report, Government of Alberta.

Grattapaglia, D., O. B. Silva-Junior, R. T. Resende, E. P. Cappa, B. S. F. Muller, B. Tan, F. Isik, B. Ratcliffe and Y. A. El-Kassaby. 2018. Quantitative genetics and genomics converge to accelerate forest tree breeding. Front. Plant Sci. 9:1693.

Hegan, R. L. and M. K. Luckert. 2000. An economic assessment of using the allowable cut effect for enhanced forest management poli- cies: An Alberta case study. Can. J. For. Res. 30 (10): 1591-1600. Holliday, J. A., S. N. Aitken, J. E. Cooke, B. Fady, S. C. GonzálezMartínez, M. Heuertz, J.-P Jaramillo-Correa, C. Lexer et al. 2017. Advances in ecological genomics in forest trees and applications to genetic resources conservation and breeding. Mol. Ecol. 26 (3): 706-717.

Hope, E. S., D. C. Barsi and D. W. McKenney. 2017. Assessing the adoption and impact of genomics research at the Canadian Forest Service. For. Chron. 93 (2): 118-121.

Howitt, R. E. 1995. Positive mathematical programming. Am. J. Agric. Econ. 77(2): 329-342.

Luckert, M. K. and D. Haley. 1995. The allowable cut effect as a policy instrument in Canadian forestry. Can. J. For. Res. 25(11): 1821-1829. McKenney, D. W., W. van Vuuren and G. C. Fox. 1989. An economic comparison of alternative tree improvement strategies: A simulation approach. Can. J. Agric. Econ. 37 (2): 211-232.

McKenney, D. W., G. C. Fox and W. van Vuuren. 1992. An economic comparison of black spruce and jack pine improvement. For. Ecol. Manag. 50 (1-2): 85-101.

Namkoong, G., H. C. Kang and J. S. Brouard. 1988. Tree breeding: Principles and strategies, Volume 11. New York, NY: Springer New York.

Paris, Q., S. Drogu and G. Anania. 2011. Calibrating spatial models of trade. Econ. Model. 28 (6): 2509-2516.

Pearse, P. H. 1990. Introduction to forestry economics. Vancouver: University of British Columbia Press.

Porth, I., G. Bull, S. Ahmed, Y. A. El-Kassaby and M. Boyland. 2015. Forest genomics research and development in Canada: Priorities for developing an economic framework. For. Chron. 91 (1): 60-70.

Porth, I., G. Q. Bull, J. Cool, N. Gelinas and V. C. Griess. 2016. An economic assessment of genomics research and development initiative projects in forestry. CAB Reviews.11 (016): 1-10.

Ratcliffe, B., O. G. El-Dien, E. P. Cappa, I. Porth, J. Klapste, C. Chen and Y. El- Kassaby. 2017. Single-step BLUP with varying genotyping effort in open-pollinated Picea glauca. G3: Genes, Genomes, Genetics 7 (3):935-942.

Remsoft Inc. 1994. Linear programming extensions to the woodstock forest modeling system. Technical report, Canadian Forest Service.

Resende, M. D. V., M. F. R. Resende, C. P. Sansaloni, C. D. Petroli, A. A. Missiaggia, A. M. Aguiar, J. M. Abad, E. K. Takahashi, A. M. Rosado et al. 2012. Genomic selection for growth and wood quality in Eucalyptus: Capturing the missing heritability and accelerating breeding for complex traits in forest trees. New Phytol. 194(1), 116-128.

Schreiber, S. G. and B. R. Thomas. 2017. Forest industry investment in tree improve- ment-a wise business decision or a bottomless pit? Answers from a new tree improvement valuation model for Alberta, Canada. For. Chron. 93 (1): 38-43.

Schweitzer, D. L., R. W. Sassaman and C. H. Schallau. 1972. Allowable cut effect: Some physical and economic implications. J. For. 70 (7): 415-418.

Statistics Canada. 2015a. Domestic exports - Wood and articles of wood; wood charcoal, Canadian International Merchandise Trade Database.

Statistics Canada. 2015b. Lumber, production, shipments and stocks [online]. Available from: https://www150.statcan.gc.ca/t1/tbl1/en/ tv.action?pid $=1610004501$.

United Nations. 2015. UN Comtrade Database [online]. Available from: https:// comtrade.un.org/data.

van Kooten, G. C. and C. Johnston. 2014. Global impacts of Russian log export restrictions and the Canada-U.S.lumber dispute: Modeling trade in logs and lumber. For Policy Econ. 39: 54-66.

White, T. L., W. T. Adams and D. B. Neale. 2007. Forest genetics. CABI Publishing, Cambridge.

Xu, J. 2006. INVITED REVIEW: Microbial ecology in the age of genomics and metagenomics: Concepts, tools, and recent advances. Mol. Ecol. 15(7): 1713-1731. 


\section{Appendix A}

Reforestation with $2^{\text {nd }}$ generation improved seeds

Figure A1 shows the pathways of developing 2nd generation improved seeds and compares the economic benefits of using $\mathrm{TB}$ and GATB. For most tree improvement programs in Alberta, first generation seed orchards are already well-developed using TB. To develop 2nd generation seed orchards, both TB and GATB techniques can be used. TB is based on pedigree selection while GATB is based on genomic selection which has been demonstrated to be more accurate than pedigree selection (Porth et al. 2015; Ratcliffe et al. 2017). Since the first generation testing is already done, the genomic tool cannot be used to shorten the breeding cycle in this case. Thus, as shown in Fig. A1, the only difference between TB and GATB is the selection method (i.e., pedigree versus genomic selection) which leads to different levels of genetic gain. It is assumed that TB produces improved seeds with 15 $\%$ genetic gain and GATB produces improved seeds with 20 $\%$ genetic gain. In both cases, the first increases in allowable cut (i.e., the ACE) are projected to occur in 2033. In this scenario, GATB is only associated with an effect of a higher selection accuracy.

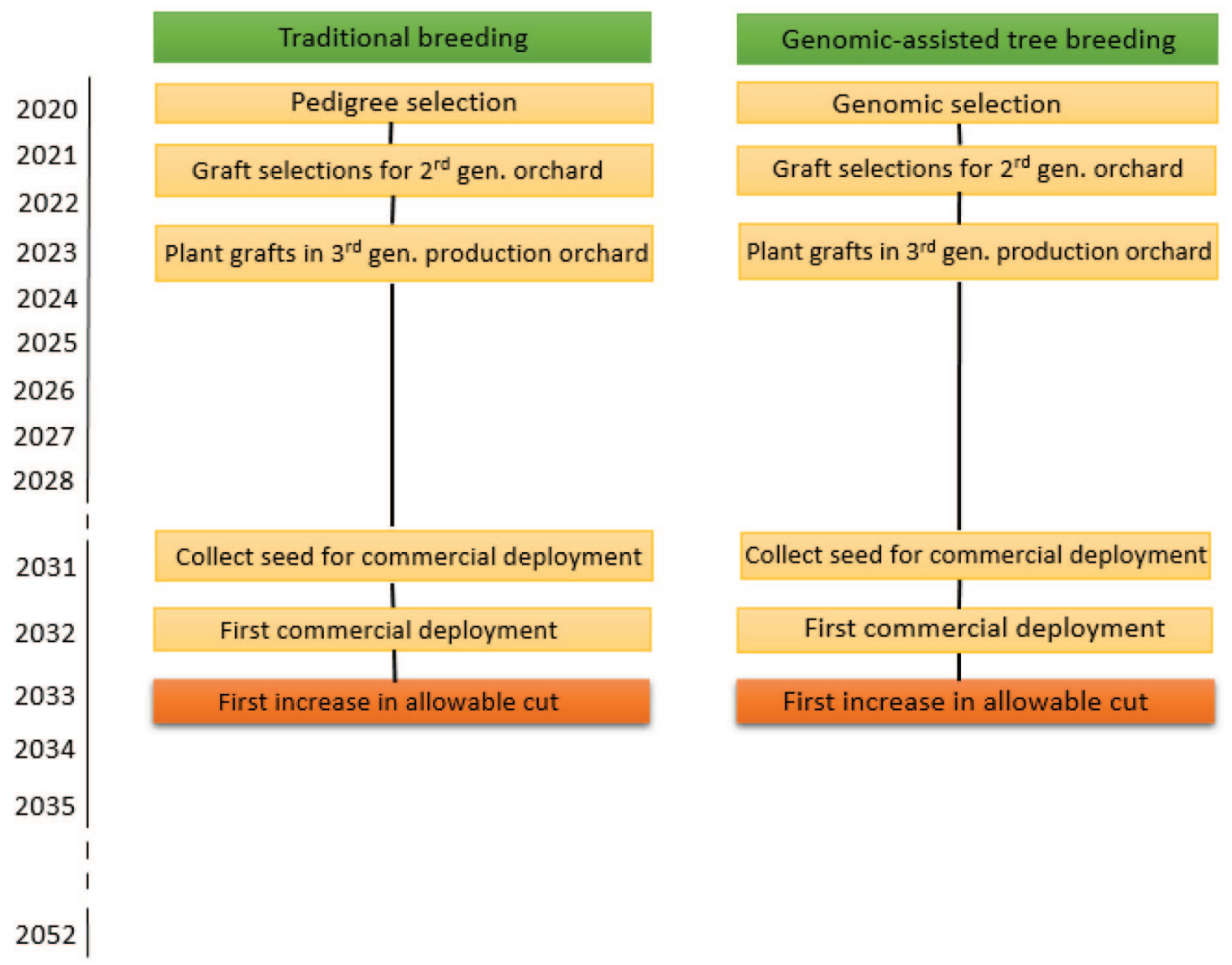

Fig. A1 Pathways of producing $2^{\text {nd }}$ generation seed orchards using TB and GATB. 


\section{Appendix B}

Reforestation with $3^{\text {rd }}$ generation improved seeds

Figure B1 shows the pathways of developing 3rd generation improved seeds and compares the economic benefits of using TB and GATB. For both breeding strategies, it is assumed that researchers cross and collect the second generation seed in the field tests and graft a new third generation orchard to produce improved seeds for reforestation. Compared with the TB approach, the genomic technology developed by the research program can shorten the testing process by 16 years $^{1}$. Additionally, using genomic selection can achieve higher genetic volume gain due to the effect of higher selection accuracy. Therefore, it is assumed that TB can be used to produce improved seeds with $25 \%$ genetic volume gain which can be used to increase the allowable cut in 2053; similarly, GATB can be used to produce improved seeds with 30 \% genetic volume gain to increase the allowable cut in 2037. In this scenario, GATB benefits from both higher selection accuracy and a shorter breeding cycle.

${ }^{1}$ Actual time-saving ranges from 13 to 20 years

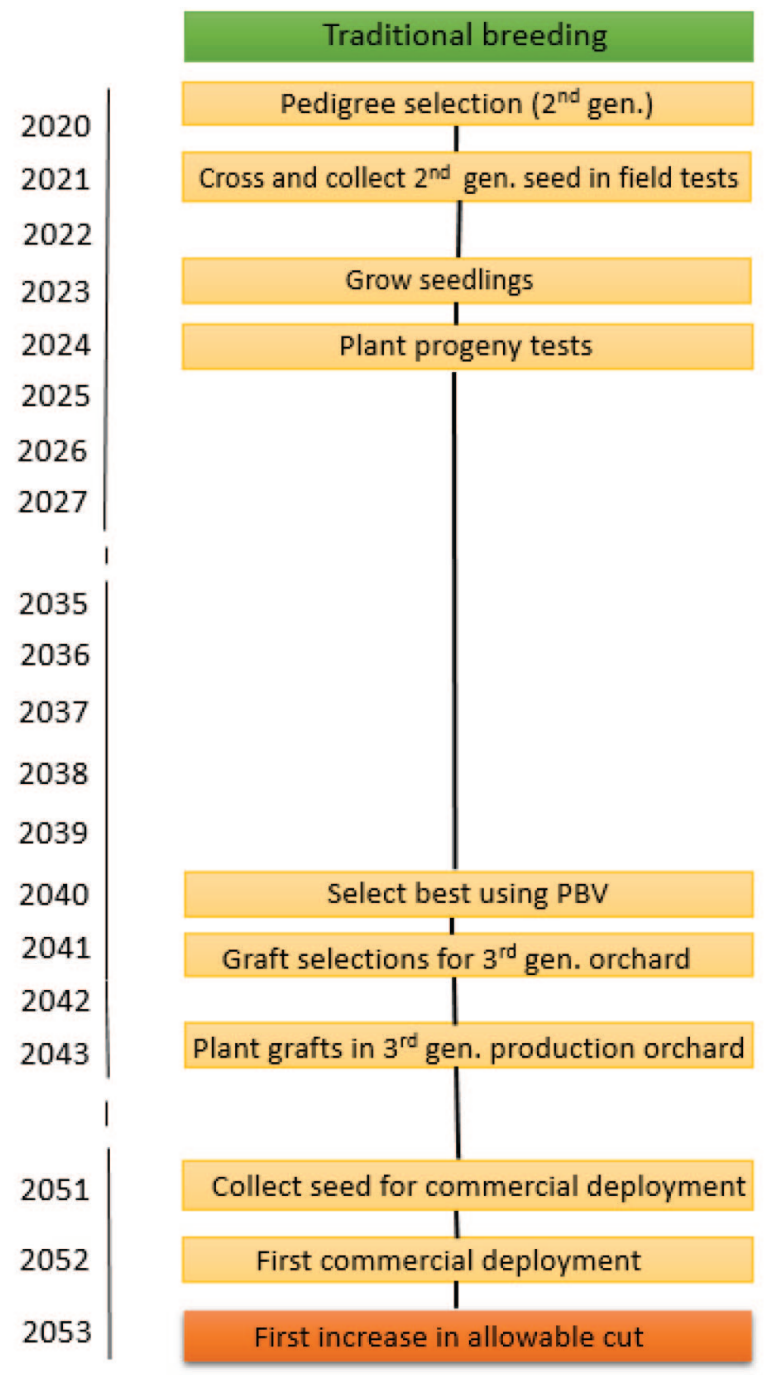

Genomic-assisted tree breeding

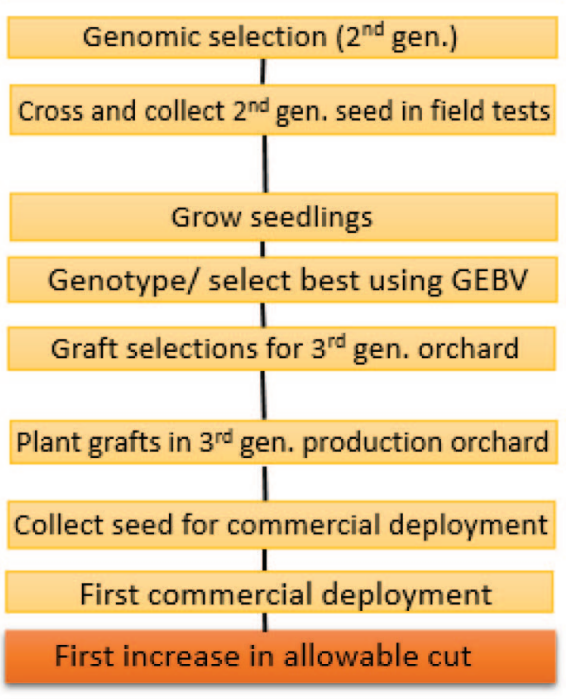

PBV $=$ Pedigree Breeding Value $\mathrm{GEBV}=$ Genomic Estimated Breeding Value

Fig. B1 Pathways of producing $3^{\text {rd }}$ generation seed orchards using TB and GATB. 


\section{Appendix C R\&D Costs}

Table C1. Research costs of phenotyping and genotyping per site

\begin{tabular}{lcc}
\hline & $\begin{array}{c}\text { Total } \\
\text { costs }\end{array}$ & $\begin{array}{l}\text { Total } \\
\text { costs } \\
\text { Activity }\end{array}$ \\
$(\$)$ & $(\%)$
\end{tabular}

Progeny Test Site Development and Phenotyping Seedling production

Test design

Site search, survey, land reservation, planning

Site development (e.g., fencing, weed control)

Planting

Establishment report, maps and database setup

Maintenance (weeding, mowing, brushing)

Herbicide application

Data collection after planting

Data collection young age

Data collection older age

Data preparation for analyses, measurement report

Data analyses and report writing

(\%)

Model Development and Genotyping

(for approximately 4800 trees)

Tissue collection

DNA extraction

Genotyping-by-sequence (GBS)

Computer Stations

10250

500

4133

71943

32600

2175

4234

7000

4500

40500

108000

4229

8700

50000

88000

456000

265000

118000

\section{Appendix D}

Global trade model

Derivation of net demand and supply

The model considers $\$ \mathrm{n} \$$ net demand regions and $\$ \mathrm{~m} \$$ net supply regions. Both supply and demand functions are assumed to be linear and therefore have constant slope ${ }^{2}$. According to Delcourt (1995), linear demand and supply are easily integrated and are robust in determining an equilibrium. In the demand function, factors that could affect lumber consumption such as the housing market, interest rates, income growth, population and technology, are not explicitly included but included as an intercept shifter. Similar to the demand function, the lumber supply function is also defined as the relationship between the quantity produced and the price. Investment in enhanced silviculture, technical change and government policy can all cause changes in future lumber supply. These factors are also included as an intercept shifter in the model. To reduce model complexity, crosseffects between products are not considered in this study.

Suppose the net demand region $i(i=1, \ldots, \mathrm{n})$ and the net supply region $j(j=1, \ldots, \mathrm{m})$ of SWL have the following linear domestic demand and supply functions:

$$
\begin{aligned}
& q_{i}^{d}=a_{i}+b_{i} \rho_{i}^{d} \\
& q_{i}^{S}=c_{i}+d_{i} \phi_{i}^{s} \\
& q_{j}^{d}=a_{j}+b_{j} \rho_{j}^{d} \\
& q_{j}^{S}=c_{j}+d_{j} \phi_{j}^{s}
\end{aligned}
$$

a period of 38 years. Cost per year is calculated by multiplying the cost per unit by the total number of units. For example: since site development cost only occurs in the first year, cost of site development is calculated by multiplying the cost per hectare (\$20 555 CAD) by total hectares (3.5 ha), which is \$71 943 CAD. Data sources: Government of Alberta.

Table C2. Operational costs of seed production per seed orchard

Activity

Seed orchard (SO) design

Forward selection (scion, wood, wood analysis)

Seed collection and seedlot prep and tests

Grafts production (rootstock, grafting, growing)

Site search, survey, land reservation, planning

Site development (fence, site logging, clearing, site prep)

Layout and planting

Irrigation system set-up

Crown management

Fertilization (materials and labour)

Herbicide and pesticide spraying (materials and labour)

PST monitoring phenology

PST monitoring growth (every $2^{\text {nd }}$ year)

Pollen contamination assessment

Irrigation (water use)

Maintenance and mowing

Pest and disease monitoring

Planning and reporting

Roguing (thinning)

Cone collection, processing, extraction and calculation $\quad 369863$

Land opportunity costs (annual agricultural land lease rate) $\quad 7657$

Total Total

costs costs

(\$)

(\%)

Data Source: Government of Alberta

$\begin{array}{rr}4350 & 0 \\ 30000 & 3 \\ 27100 & 3 \\ 48140 & 5 \\ 2742 & 0 \\ 36110 & 4 \\ 5438 & 1 \\ 10000 & 1 \\ 55000 & 6 \\ 24800 & 3 \\ 14000 & 2 \\ 33750 & 4 \\ 3250 & 0 \\ 12150 & 1 \\ 14570 & 2 \\ 81530 & 9 \\ 30000 & 3 \\ 67425 & 8 \\ 0 & 0 \\ 369863 & 42 \\ 7657 & 1\end{array}$

$\overline{{ }^{2} \mathrm{~A} \text { change in slope may pose a problem in solving }}$ for equilibrium values (Chang and Gaston 2014). 


$$
\begin{aligned}
& a_{j}=q_{j}^{d}-b_{j} \rho_{j}^{d} \\
& d_{j}=e_{j}^{s}\left(\frac{q_{j}^{s}}{\phi_{j}^{s}}\right) \\
& c_{j}=q_{j}^{s}-d_{j} \phi_{j}^{s}
\end{aligned}
$$

Where, $e_{i}^{d}, e_{i}^{s}$ and $e_{j}^{d}, e_{j}^{s}$ represent the own-price elasticities of domestic demand and supply of SWL in regions $i$ and $j$, respectively. To derive the net demand and supply functions, net demand and supply elasticities are required and can be calculated as follows:

$$
\begin{gathered}
\varepsilon_{i}^{d}=e_{i}^{d}\left(\frac{q_{i}^{d}}{M_{i}}\right)-e_{i}^{s}\left(\frac{q_{i}^{s}}{M_{i}}\right) \\
\varepsilon_{j}^{s}=e_{j}^{s}\left(\frac{q_{j}^{s}}{X_{j}}\right)-e_{j}^{d}\left(\frac{q_{j}^{d}}{X_{j}}\right)
\end{gathered}
$$

Where $\varepsilon_{i}^{d}$, is the net demand elasticity in region $i$ and $\varepsilon_{j}^{s}$ is the net supply elasticity in region $j . M_{i}$ is the import quantity of SWL in region $i$ and $X_{j}$ is the export quantity of SWL in region $j$. The intercepts and slopes of the net demand and net supply functions can be derived as follows:

$$
\begin{gathered}
\alpha_{i}=\frac{\left(c_{i}-a_{i}\right)}{\left(b_{i}-d_{i}\right)} \\
\beta_{i}=\frac{1}{\left[\varepsilon_{i}^{d}\left(\frac{M_{i}}{\rho_{i}^{d}}\right)\right]} \\
\gamma_{j}=\frac{\left(c_{j}-a_{j}\right)}{\left(b_{j}-d_{j}\right)} \\
\sigma_{j}=\frac{1}{\left[\varepsilon_{j}^{d}\left(\frac{X_{j}}{\phi_{j}^{s}}\right)\right]}
\end{gathered}
$$

It is assumed that changes in consumption and production for each time period can be measured by changing the intercepts of domestic demand and supply functions. Specifically, the intercepts of domestic demand and supply functions are defined as:

$$
\begin{aligned}
& a_{i(t+1)}=a_{i t}+q_{i t}^{d}\left(R_{i}^{D}\right)[(t+1)-t] \\
& c_{i(t+1)}=c_{i t}+q_{i t}^{s}\left(R_{i}^{S}\right)[(t+1)-t] \\
& a_{j(t+1)}=a_{j t}+q_{j t}^{d}\left(R_{j}^{D}\right)[(t+1)-t] \\
& c_{j(t+1)}=c_{j t}+q_{j t}^{s}\left(R_{j}^{S}\right)[(t+1)-t]
\end{aligned}
$$

Where $t+1$ is the year of the next period and $t$ is the year of the current period. $R_{i}^{D}$ and $R_{j}^{D}$ are the expected annual SWL demand changes (\%) in regions $i$ and $j$, respectively. $R_{i}^{D}$ and
$R_{j}^{S}$ are the expected annual SWL supply changes (\%) in regions $i$ and $j$, respectively. Since the intercept parameters of the domestic demand and supply functions are updated for each year, the intercept parameters of the net demand and supply functions in the model are also changed accordingly.

\section{Positive mathematical programming}

Samuelson (1952) and Takayama and Judge (1971) showed that the optimal trade flow can be determined using a mathematical programming model. The specification of a spatial trade model among regions corresponds to the maximization of a quasi-welfare function (QWF) subject to constraints regarding the demand and the supply of the various regions. The QWF objective function is defined as the sum of all regional demand integrals less the sum of all regional supply integrals and interregional transportation costs, which corresponds to the maximization of the sum of consumers' and producers' surpluses netted out of total transaction costs (Samuelson 1952; Takayama and Judge 1971), or:

(28) $\operatorname{Max} \sum_{i=1}^{n} \int_{0}^{M_{i}} D_{i}\left(M_{i}\right) d M_{i}-\sum_{j=1}^{m} \int_{0}^{X_{j}} S_{j}\left(X_{j}\right) d X_{j}-\sum_{i=1}^{n} \sum_{j=1}^{m} t_{i j} Q_{i j}$

Where $D_{i}$ and $S_{j}$ are the demand and supply of SWL for the regions; $Q_{i j}$ is the quantity of SWL exported from region $j$ to region $i ; t_{i j}$ is the per unit transportation cost of SWL from region $j$ to region $i$. The transportation costs among different regions are considered to obtain the competitive optimum solution for regional prices and quantities and interregional flows when total economic welfare (trade surplus) of all markets is maximized. To be used in the algorithm of the objective function, the net demand and supply equations are assumed in its inverted form. The inverse demand and supply functions are derived from the domestic demand and supply functions in each region as follows:

$$
\begin{aligned}
& P_{i}^{d}=\alpha_{i}-\beta_{i} M_{i}, \quad i=1, \ldots n \\
& P_{j}^{s}=\gamma_{j}-\delta_{j} X_{j}, \quad j=1, \ldots . m
\end{aligned}
$$

Where $\alpha_{i}$ and $\beta_{i}$ denote the intercept and slope of the net demand function of SWL, and the variables $P_{i}^{d}$ and $M_{i}$ represent the demand (import) price and total quantity demand (imports) of SWL for region $i$, respectively. $y_{j}$ and $\delta_{j}$ are the intercept and slope of the net supply function of SWL, and the variable $P_{j}^{s}$ and $X_{j}$ denote the supply (export) price and total supply (exports) of SWL for region $j$. Therefore, the integrals of eq. (28) can be expressed in terms of the quadratic function in eq. (31) along with the related constraints in eqs. (32-35):

$$
\operatorname{Max} \sum_{i=1}^{n}\left[\alpha_{i} M_{i}-\frac{1}{2} \beta_{i}\left(M_{i}\right)^{2}\right]-\sum_{j=1}^{m}\left[\gamma_{j} X_{j}+\frac{1}{2} \sigma_{j}\left(X_{j}\right)^{2}\right]-\sum_{i=1}^{n} \sum_{j=1}^{m} t_{i j} Q_{i j}
$$

Subject to:

$$
\sum_{i}^{n} Q_{i j} \leq X_{j}
$$




$$
\sum_{j=1}^{m} Q_{i j} \geq M_{i}
$$

$$
\begin{aligned}
& M_{i}, X_{j}, Q_{i j} \geq 0 \\
& \sum_{i=1}^{n} M_{i}-\sum_{j=1}^{m} X_{j}=0
\end{aligned}
$$

Constraint (32) ensures that the SWL supply of region $j$ is greater or equal to the total export of SWL in region $j$. Constraint (33) ensures that the total SWL import of region $i$ is at least as big as what is consumed in region $i$; constraint (34) ensures prices and quantities are positive; and constraint (35) ensures that the markets clear.

The standard mathematical model proposed by Samuelson (1952) and Takayama and Judge (1971) is critiqued by Paris et al. (2011) for the discrepancy between the equilibrium solution and the observed demand, supply and level of trade flows. The cause of the discrepancy problem can be attributed to the imprecision of unit transaction cost (Paris et al. 2011). To generate solutions that perfectly reproduce observed supply and demand quantities as well as prices and trade flows for a given base year, we adopted the calibration method proposed by Paris et al. (2011), which is an extension of the positive mathematical programming method (Howitt 1995). Specifically, the unit transaction costs are further adjusted by either adding or subtracting the shadow price from the level of the given costs (Paris et al. 2011).

Following Paris et al. (2011), van Kooten and Johnston (2014) and Chang and Gaston (2014), the calibration process is implemented in three steps. First, the objective function (eq. 28) is solved, subject to all the constraints (eqs. 32-35) and an additional calibration constraint (eq. 36):

$$
Q_{i j}=Q_{i j}^{\prime}
$$

Where $Q_{i j}^{\prime}$ represents the observed trade flow of lumber between export region $j$ and import region $i$.

After solving the model, the dual (shadow) prices $\lambda$ ij are generated. Secondly, the shadow prices generated in the first step are used to adjust the original transportation costs in the objective function to achieve the "effective" transaction costs between export and import regions. The new objective function is as follows:

$$
\begin{aligned}
\operatorname{Max} & \sum_{i=1}^{n} \int_{0}^{M_{i}} D_{i}\left(M_{i}\right) d M_{i}-\sum_{j=1}^{m} \int_{0}^{X_{j}} S_{j}\left(X_{j}\right) d X_{j} \\
& -\sum_{i=1}^{n} \sum_{j=1}^{m}\left(t_{i j}+\lambda_{i j}\right) Q_{i j}
\end{aligned}
$$

Finally, the modified objective function (eq. 37) is solved again, subject to the original constraints (eqs. 32-35) in order to calibrate the spatial equilibrium model perfectly to the observed trade flows, quantities of production and consumption and prices. The model is solved using the Microsoft Excel software package What's Best!. It allows users to try different trade scenarios, perform sensitivity analyses or impose additional constraints with little difficulty (Chang and Gaston

\begin{tabular}{|c|c|c|c|c|c|c|c|c|}
\hline & \multicolumn{2}{|c|}{ Production } & \multicolumn{2}{|c|}{ Consumption } & \multicolumn{2}{|c|}{ Trade } & \multicolumn{2}{|c|}{ Price } \\
\hline & $\begin{array}{c}\text { Million } \\
\left(\mathbf{m}^{3}\right)\end{array}$ & $\begin{array}{c}\% \text { of } \\
\text { actual level }\end{array}$ & $\begin{array}{l}\text { Million } \\
\left(\mathbf{m}^{3}\right)\end{array}$ & $\begin{array}{c}\% \text { of } \\
\text { actual level }\end{array}$ & $\begin{array}{l}\text { Million } \\
\left(\mathbf{m}^{3}\right)\end{array}$ & $\begin{array}{c}\% \text { of } \\
\text { actual level }\end{array}$ & $\begin{array}{c}\text { CAD\$ } \\
\left(\mathrm{m}^{-3}\right)\end{array}$ & $\begin{array}{c}\% \text { of } \\
\text { actual level }\end{array}$ \\
\hline \multicolumn{9}{|l|}{ Export } \\
\hline $\mathrm{AB}$ & 9.27 & 100 & 5.50 & 100 & 3.77 & 100 & 171 & 100 \\
\hline $\mathrm{BC}$ & 31.18 & 100 & 4.98 & 100 & 26.20 & 100 & 221 & 100 \\
\hline ROC & 22.53 & 100 & 11.14 & 100 & 11.38 & 100 & 181 & 100 \\
\hline ROW_ex & 101.55 & 100 & 40.51 & 100 & 61.04 & 100 & 350 & 100 \\
\hline \multicolumn{9}{|l|}{ Import } \\
\hline U.S. & 54.33 & 100 & 86.70 & 100 & 32.36 & 100 & 204 & 100 \\
\hline ROW_im & 164.71 & 100 & 234.74 & 100 & 70.03 & 100 & 332 & 100 \\
\hline
\end{tabular}
2014). Table D1 presents calibrated SWL production, consumption, trade, and prices for the spatial equilibrium model in the base year of 2015 .

Table D1. Calibrated softwood lumber production, consumption, trade, and prices for the trade model and comparisons with the actual levels in base year 2015

Note: Adjustments in the form of shadow prices are used to calibrate the model to the observed trade flows. The acronyms of the regions are defined in the footnote of Table 1. 


\section{Appendix References}

Chang, W.-Y. and C. Gaston. 2014. The competitiveness of Canadian softwood lumber: A disaggregated trade-flow analysis. Can. J. For. Res. 44(12), 1494-1506.

Howitt, R. E. 1995. Positive mathematical programming. Am J Agric Econ. 77(2): 329-342.

Paris, Q., S. Drogu and G. Anania. 2011. Calibrating spatial models of trade. Econ. Model. 28 (6): 2509-2516.

Samuelson, P. A. 1952. Spatial price equilibrium and linear programming. Am Econ Rev. 42 (3): 283-303.
Takayama, T. and G. G. Judge. 1971. Spatial and temporal price and allocation models. Technical report, North-Holland Amsterdam.

van Kooten, G. C. and C. Johnston. 2014. Global impacts of Russian log export restrictions and the Canada-U.S.lumber dispute: Modeling trade in logs and lumber. For. Policy Econ. 39: 54-66. 